\title{
Reaction Kinetics of $\mathrm{CO}$ and $\mathrm{CO}_{2}$ Methanation over Nickel
}

\author{
Daniel Schmider, Lubow Maier, and Olaf Deutschmann*
}

Cite This: Ind. Eng. Chem. Res. 2021, 60, 5792-5805

Read Online

ABSTRACT: Methanation of both $\mathrm{CO}$ and $\mathrm{CO}_{2}$ with electrolysissourced hydrogen is a key step in power-to-gas technologies with nickel as the most prominent catalyst. Here, a detailed, thermodynamically consistent reaction mechanism for the methanation reactions of $\mathrm{CO}$ and $\mathrm{CO}_{2}$ over Ni-based catalysts is presented. This microkinetic model is based on the mean-field approximation and comprises 42 reactions among 19 species. The model was developed based on experiments from a number of studies in powder and monolith catalysts. These are numerically reproduced by flow field simulations coupled with the kinetic scheme. The reaction mechanism features multiple paths for the conversion of $\mathrm{CO}$ and $\mathrm{CO}_{2}$ into $\mathrm{CH}_{4}$, including a carbide pathway and

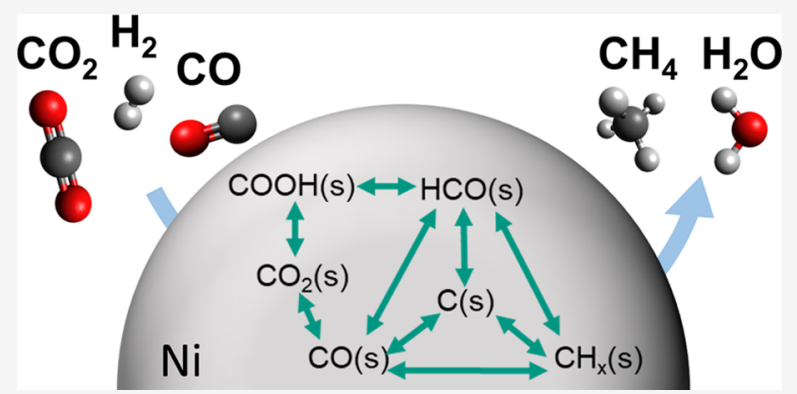
direct hydrogenation of $\mathrm{CO}_{2}$ on the surface. The model developed describes the methanation process adequately over a wide range of temperatures, catalyst loadings, support materials, and reactant ratios. Hence, it can serve as a microkinetic basis for reaction engineering and up-scaling purposes.

\section{INTRODUCTION}

The catalytic methanation of $\mathrm{CO}$ and/or $\mathrm{CO}_{2}$, a key step in power-to-gas $(\mathrm{PtG})$ technologies, has been extensively investigated. The production of synthetic natural gas (SNG) from hydrogen coming from electrolyzers is of special interest for the storage of renewable electrical energy in the form of hydrocarbons, ${ }^{1,2}$ especially as many regions already possess an extensive natural gas grid. Since water is the only significant side product of methanation, the product stream is rather easily introducible into the natural gas grid after dehydration. $\mathrm{CO}_{2}$ and combined $\mathrm{CO} / \mathrm{CO}_{2}$ methanation also is of interest for $\mathrm{CO}_{2}$ point sources such as typical steel plant, where large portions of the exhaust gases consist of $\mathrm{CO}$ and $\mathrm{CO}_{2}{ }^{3}$

The catalytic methanation of $\mathrm{CO}$ and $\mathrm{CO}_{2}$ has been studied since its discovery by Sabatier and Senderens in $1902 .{ }^{4}$ The primary application of this reaction has been the purification of syngases via the removal of $\mathrm{CO}$. The commercial conversion of $\mathrm{CO}$ to $\mathrm{CH}_{4}$ is primarily realized over a $\mathrm{Ni}$ catalyst.

$$
\mathrm{CO}+3 \mathrm{H}_{2} \rightleftharpoons \mathrm{CH}_{4}+\mathrm{H}_{2} \mathrm{O}, \quad \Delta_{\mathrm{R}} \mathrm{H}=-206.2 \mathrm{~kJ} \mathrm{~mol}^{-1}
$$

While $\mathrm{CO}_{2}$ methanation research was largely a byproduct of work on $\mathrm{CO}$ methanation, it has attracted more attention recently. ${ }^{5-8}$ Generally, $\mathrm{Ni}$ is also primarily used as the catalyst, with $\mathrm{Ru}$ also drawing some interest. ${ }^{5}$

$$
\mathrm{CO}_{2}+4 \mathrm{H}_{2} \rightleftharpoons \mathrm{CH}_{4}+2 \mathrm{H}_{2} \mathrm{O}, \quad \Delta_{\mathrm{R}} \mathrm{H}=-165.0 \mathrm{~kJ} \mathrm{~mol}^{-1}
$$

Both reactions are highly exothermic; thus, high temperatures are unfavorable to the conversion of the carbon oxides. Additionally, high pressures are very conducive to high methane yields. Due to the species partaking in these reactions, the water-gas shift (WGS) reaction (3) needs to be taken into account when dealing with methanation systems.

$$
\mathrm{CO}+\mathrm{H}_{2} \mathrm{O} \rightleftharpoons \mathrm{CO}_{2}+\mathrm{H}_{2}, \quad \Delta_{\mathrm{R}} H=-41.2 \mathrm{~kJ} \mathrm{~mol}^{-1}
$$

The reverse water-gas shift reaction (RWGS) utilizes the same reactants as $\mathrm{CO}_{2}$ methanation; therefore, in experiments of this kind, there will likely be $\mathrm{CO}$ evolution alongside $\mathrm{CH}_{4}$ production. At the same time, interconversion between $\mathrm{CO}$ and $\mathrm{CO}_{2}$ as well as reforming reactions of the produced $\mathrm{CH}_{4}$ may also take place. A typical issue for carbon-containing reaction processes over $\mathrm{Ni}$ catalysts is coke formation on the active component. ${ }^{9}$ These many chemical interactions rather call for a microkinetic model, i.e., a detailed, multistep surface reaction mechanism with associated kinetic and thermodynamic data, than a macrokinetic description. The microkinetic model should include all relevant species and possible reaction routes from/to $\mathrm{CO}$ and $\mathrm{CO}_{2}$ to/from $\mathrm{CH}_{4}$ as well as WGS and RWGS and be tested for a wide range of conditions.

The elementary steps of $\mathrm{CO}$ and $\mathrm{CO}_{2}$ methanation over $\mathrm{Ni}$ catalysts have been extensively studied over time. It is generally accepted that the activation of $\mathrm{CO}$ is achieved via associative adsorption. This is supported by experimental findings supporting the argument that associative $\mathrm{CO}$ adsorption

Received: January 27, 2021

Revised: March 17, 2021

Accepted: March 23, 2021

Published: April 19, 2021 
Table 1. Summary of Experiments Used for the Development and Validation of the Kinetic Model

\begin{tabular}{|c|c|c|c|c|c|c|c|c|c|c|}
\hline $\exp$ & catalyst & $L(\mathrm{~mm})$ & $D(\mathrm{~mm})$ & $m_{\text {cat }}(\mathrm{g})$ & $d_{\mathrm{P}}(\mu \mathrm{m})$ & $\operatorname{SSA}\left(\mathrm{m}^{2} \mathrm{~g}^{-1}\right)$ & $u\left(\mathrm{~m} \mathrm{~s}^{-1}\right)$ & $T(\mathrm{~K})$ & feed gas: $\mathrm{CO}_{2} / \mathrm{CO} / \mathrm{H}_{2} /$ inert $(\mathrm{mol} \%)$ & ref \\
\hline 1 & $\mathrm{Ni} / \mathrm{Al}_{2} \mathrm{O}_{3}{ }^{a, b}$ & 12 & 0.88 & & & & 0.514 & $373-873$ & $2 / 0 / 7 / 91$ & 36 \\
\hline 2 & $20 \% \mathrm{Ni} / \mathrm{Al}_{2} \mathrm{O}_{3}$ & 36.4 & 8 & 0.5 & 630 & 14 & 0.217 & $453-873$ & $0 / 20 / 60 / 20$ & 37 \\
\hline 3 & $20 \% \mathrm{Ni} / \mathrm{Al}_{2} \mathrm{O}_{3}$ & 1.02 & 10 & 0.2 & 375 & 3.56 & 0.017 & $477-773$ & $0 / 25 / 75 / 0$ & 38 \\
\hline 4 & $10 \% \mathrm{Ni} / \mathrm{SiO}_{2}$ & 2.87 & 3 & 0.05 & 265 & 2.81 & 0.616 & $423-593$ & $0 / 1 / 50 / 49$ & 39 \\
\hline 5 & $5 \% \mathrm{Ni} / \mathrm{SiO}_{2}$ & 48 & 3.77 & 0.18 & 3000 & 1.1 & 0.14 & $467-583$ & $0 / 6 / 18 / 76$ & 40 \\
\hline 6 & $\mathrm{Ni} / \mathrm{Al}_{2} \mathrm{O}_{3}^{a, b}$ & 12 & 0.88 & & & & 0.514 & $373-973$ & $4 / 0 / 5.3 / 90.7$ & 36 \\
\hline 7 & $10 \% \mathrm{Ni} / \mathrm{MgAl}_{2} \mathrm{O}_{4}$ & 12.1 & 8 & 1.2 & 335 & 4.55 & 0.044 & $523-773$ & $16 / 0 / 64 / 20$ & 41 \\
\hline 8 & $20 \% \mathrm{Ni} / \mathrm{Al}_{2} \mathrm{O}_{3}$ & 1.02 & 10 & 0.2 & 375 & 3.56 & 0.017 & $477-773$ & $22.2 / 0 / 77.8 / 0$ & 38 \\
\hline 9 & $40.8 \% \mathrm{NiAlO}_{x}{ }^{c}$ & 7.98 & 4 & 0.025 & 175 & 8.28 & 0.22 & $430-717$ & $10 / 0 / 40 / 50$ & 35 \\
\hline 10 & $\mathrm{Ni} / \mathrm{Al}_{2} \mathrm{O}_{3}{ }^{a, b, d}$ & 100 & 33 & & & & 0.0088 & $503-573$ & $17.6 / 11.8 / 35.5 / 30.3$ & 36 \\
\hline 11 & $5 \% \mathrm{Ni} / \mathrm{ZrO}_{2}$ & 1.81 & 6.5 & 0.15 & 220 & 1.826 & 0.174 & $423-623$ & $17 / 0.6 / 57 / 25.4$ & 42 \\
\hline 12 & $10 \% \mathrm{Ni} / \mathrm{ZrO}_{2}^{e}$ & 2.87 & 3 & 0.05 & 265 & 3.06 & 0.616 & $423-593$ & $0 / 1 / 50 / 49$ & 39 \\
\hline 13 & $10 \% \mathrm{Ni} / \mathrm{ZrO}_{2}{ }^{e}$ & 2.87 & 3 & 0.05 & 265 & 3.06 & 0.616 & $463-617$ & $1 / 0 / 50 / 49$ & 39 \\
\hline 14 & $10 \% \mathrm{Ni} / \mathrm{SiO}_{2}{ }^{e}$ & 2.87 & 3 & 0.05 & 265 & 2.81 & 0.616 & $463-617$ & $1 / 0 / 50 / 49$ & 39 \\
\hline 15 & $\mathrm{Ni}^{b, e, f}$ & 30 & 10 & 1.76 & 750 & & 0.514 & $373-1073$ & $4 / 0 / 5.1 / 90.9$ & 36 \\
\hline 16 & $15 \% \mathrm{Ni} / \mathrm{Al}_{2} \mathrm{O}_{3}^{e}$ & 9.71 & 8 & 0.3 & 630 & 8.72 & 0.21 & $523-773$ & $18 / 0 / 72 / 0$ & 43 \\
\hline 17 & $10 \% \mathrm{Ni} / \mathrm{MgAl}_{2} \mathrm{O}_{4}{ }^{e}$ & 12.1 & 8 & 1.2 & 335 & 3.84 & 0.044 & $523-773$ & $16 / 0 / 64 / 20$ & 41 \\
\hline 18 & $5 \% \mathrm{Ni} / \mathrm{SiO}_{2}^{e}$ & 48 & 3.77 & 0.18 & 3000 & 1.1 & 0.14 & $483-673$ & $6 / 6 / 88 / 0$ & 44 \\
\hline 19 & $5 \% \mathrm{Ni} / \mathrm{TiO}_{2}^{e}$ & 1.81 & 6.5 & 0.15 & 220 & 1.281 & 0.174 & $423-623$ & $17 / 0.6 / 57 / 25.4$ & 42 \\
\hline 20 & $5 \% \mathrm{Ni} / \mathrm{Al}_{2} \mathrm{O}_{3}{ }^{e}$ & 1.81 & 6.5 & 0.15 & 220 & 0.897 & 0.174 & $423-623$ & $17 / 0.6 / 57 / 25.4$ & 42 \\
\hline
\end{tabular}

${ }^{a}$ Monolithic catalyst. ${ }^{b}$ Exact catalyst parameters are confidential. ${ }^{c}$ Experiment was conducted at 8 bar. ${ }^{d}$ Experiment was conducted at 1.8 bar and with $4.1 \% \mathrm{CH}_{4}$ and $59 \mathrm{ppm} \mathrm{O}_{2}$ in the gas feed. ${ }^{e}$ Validation results are found in the Supporting Information. ${ }^{f}$ Commercial catalyst provided by BASF.

competes with dissociative $\mathrm{H}_{2}$ adsorption on the surface. ${ }^{10}$ Subsequently, $\mathrm{CO}(\mathrm{s})$ (s denotes surface species) dissociates to form a surface carbide species, the hydrogenation of which is thought to be the rate-limiting step (RLS), possibly alongside the dissociation itself. ${ }^{11}$ Evidence toward this conclusion has been brought forth using dynamic response studies. ${ }^{12}$ Carbon formation on the $\mathrm{Ni}$ surface may also be the result of the Boudouard reaction, the disproportionation of $\mathrm{CO}(\mathrm{s})$ to $\mathrm{CO}_{2}(\mathrm{~s})$ and surface carbide. ${ }^{13}$ While it was originally believed that $\mathrm{CO}$ methanation on $\mathrm{Ni}$ proceeds via oxygenated intermediates such as methanol or formaldehyde, surface studies have not confirmed the presence of such species. ${ }^{14}$

The mechanism of $\mathrm{CO}_{2}$ methanation is a topic of discussion, and its exact route is not generally agreed upon, with experiments at different conditions leading to varying suggestions about the exact pathway. The adsorbed $\mathrm{CO}_{2}$ could react in one or possibly both of two ways: it might dissociate and form $\mathrm{CO}(\mathrm{s})$, from where it follows the $\mathrm{CO}$ methanation mechanism via a surface carbide species (RWGS path). This mechanism was suggested following $\mathrm{CO}_{2}$ methanation investigations ${ }^{15}$ and after $\mathrm{CO}_{2}$ pulse adsorption studies. ${ }^{16}$ Alternatively, $\mathrm{CO}_{2}(\mathrm{~s})$ might react with hydrogen directly and form oxygenated species such as carboxyl, $\mathrm{COOH}(\mathrm{s})$, or formate, $\mathrm{HCOO}(\mathrm{s})$, which then dissociate and form $\mathrm{CO}(\mathrm{s})$ or are further hydrogenated toward methane (direct hydrogenation path). In situ diffuse reflectance spectroscopy studies of $\mathrm{CO}_{2}$ methanation have shown the formation of formate and carbonate species above $383 \mathrm{~K}^{17}$ Density functional theory (DFT) calculations have shown that the direct dissociation into $\mathrm{CO}(\mathrm{s})$ and $\mathrm{O}(\mathrm{s})$ is favorable energetically compared to the formation of formate (bonded to the surface via one or two oxygen atoms).$^{18}$ Other DFT results indicate that the formation of carboxyl (bonded to the surface at the carbon atom) is more favorable than dissociation into $\mathrm{CO}(\mathrm{s})$ and $\mathrm{O}(\mathrm{s}) .{ }^{19}$ On the basis of DFT calculations and reaction flow analysis, the carboxyl intermediate $\mathrm{COOH}(\mathrm{s})$ was also determined as the most abundant species in the WGS reaction. $^{20}$

There is also evidence for the variation of the reaction path based on the support material of Ni catalysts. This might be a consequence of the catalyst structure, i.e., particle size and exposed crystal faces, adsorption and desorption characteristics of the support material, and a difference in the dominant reaction pathways taken. A good summary is provided in a recent review. ${ }^{21}$ While on more inert supports, the direct dissociation of $\mathrm{CO}_{2}$ and the participation of formate are expected, ${ }^{2-24}$ the adsorption of $\mathrm{CO}_{2}$ and the formation of carbonate species on the support itself have been proposed for more basic materials. ${ }^{25,26}$

The proposed rate-determining steps in the $\mathrm{CO}_{2}$ methanation mechanism are the dissociation of $\mathrm{CO}(\mathrm{s})$ and the following hydrogenation of $\mathrm{CH}_{x}(\mathrm{~s})$, depending on reaction conditions. ${ }^{7}$ However, it is disputed which step is rate-limiting at which conditions. For example, $\mathrm{CO}(\mathrm{s})$ dissociation has been suggested as the rate-limiting step (RLS) between 270 and 400 ${ }^{\circ} \mathrm{C}$, ${ }^{10}$ while it is ruled out elsewhere, at least for temperatures below $284{ }^{\circ} \mathrm{C} .{ }^{27}$

Alternative pathways have also been proposed: a dioxymethylene $\left(\mathrm{C}(\mathrm{OH})_{2}(\mathrm{~s})\right)$ species was originally proposed by Medsforth in $1923,{ }^{28}$ but does not represent a likely intermediate from an energetic standpoint. ${ }^{18} \mathrm{~A}$ possible pathway to formate in an Eley-Rideal-type mechanism was presented in another publication based on $\mathrm{DFT}^{29}$ it is however ruled out as an intermediate on the way to methane as the authors assume its hydrogenation to unstable formic acid $\mathrm{HCOOH}(\mathrm{s})$, which decomposes back into formate, forming a dead end to the reaction path. Other studies have argued in favor of an Eley-Rideal mechanism based on gravimetric analysis of a $\mathrm{Ni}$ catalyst. $^{30}$ Reasoned from energetic calculations, the presence of additional hydrogenated intermediates such as $\mathrm{H}_{2} \mathrm{COH}(\mathrm{s})$ or $\mathrm{H}_{3} \mathrm{CO}(\mathrm{s})$ is also considered. ${ }^{31}$ 
So far, the $\mathrm{CO}$ and $\mathrm{CO}_{2}$ methanation reactions over $\mathrm{Ni}$ have not been described using an elementary, thermodynamically consistent mechanism that includes both reactants. However, there is a multitude of global kinetics available, some of which include both $\mathrm{CO}$ and $\mathrm{CO}_{2}$ conversion terms. ${ }^{15,27,32-35}$ Such models are in general constrained to the systems they were developed from and their application outside the conditions they were developed from is risky. Additionally, a significant number of these models neglect kinetic reversibility and are therefore not suitable to describe the equilibrium composition adequately.

The objective of this work is the development of the detailed, thermodynamically consistent surface reaction mechanism for the methanation of $\mathrm{CO}$ and $\mathrm{CO}_{2}$ over $\mathrm{Ni}$ based catalysts using the mean-field approximation. Our microkinetic model is based on theoretical investigations as well as a number of experimental studies both conducted inhouse and from the literature. This dataset encompasses experiments in both fixed-bed and monolithic reactors under various conditions.

\section{METHODS}

2.1. Collection of Experimental Data. A number of experiments, 20 in total collected from 9 publications, were

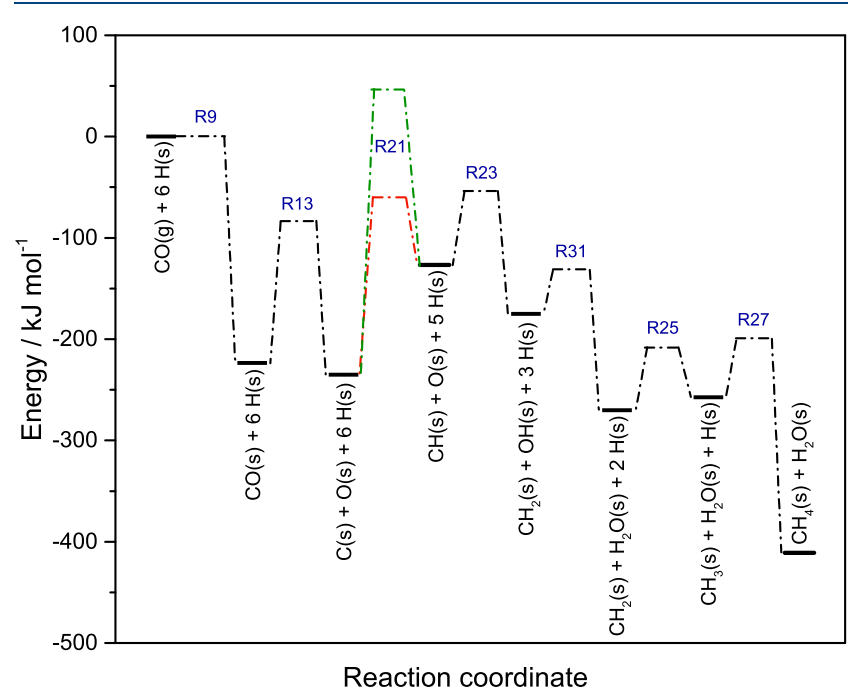

Figure 1. Potential energy diagram of one possible $\mathrm{CH}_{4}$ formation path from CO. Potential energy levels of the named species, solid lines; transition states, dashed lines. For reaction 21, the transition state with an assumed: $\theta_{\mathrm{C}}=0$ in green, $\theta_{\mathrm{C}}=1$ in red.

used to develop and validate the kinetic model. Data from the literature and from in-house experiments were utilized. ${ }^{36}$ While experimental data on methanation is abundant in the literature, not all publications contain the parameters necessary for a computational replication. To model the reactor accurately, information about several properties is needed, including its dimensions (length, diameter), the catalyst (mass, particle size, active surface), and the gas flow (temperature, pressure, velocity/flow, composition). Some of these values may be calculated or approximated if not given explicitly. As an example, the active catalytic area might be estimated based on the reported size of the metal nanoparticles. Respecting these restrictions, the literature was screened for suitable data. The experiments used for the development of this model are listed in Table 1. Experiments spanning a wide range of parameters, including catalyst supports, metal loadings, space velocities, and reactor dimensions, were selected.

2.2. Modeling Approach. The numerical simulations of the reactor configurations were performed using the DETCHEM $^{\text {CHANNEL }}$ code, part of the DETCHEM program package. ${ }^{45}$ For experiments conducted in a monolithic reactor, a single channel is simulated using the conditions listed in the corresponding reference. For fixed-bed experiments, the reactor is replicated by simulating an imaginary path through the fixed bed as a channel. The dimensions of this cylindrical reactor are calculated based on the properties of the packed bed using an approximation that estimates the channel diameter to be equal to that of the powder bed particles. ${ }^{46}$ The velocity of the reactive flow is corrected for the gain in open surface area in a channel compared to a fixed bed. The volumetric flow rate and, consequently, the linear velocity are recalculated using the bed porosity to obtain a value for the open-faced area fraction. The porosity, if not stated explicitly, is calculated using the approximation by Pushnov. ${ }^{47}$ An available simulation code for fixed-bed reactors was not compatible with all parameters from the dataset. For the remaining experiments, the results of channel and fixed-bed simulations agreed very well. The code resolves the path of the reacting flow through the equivalent channel in the steady state two-dimensionally using the boundary layer approximation. This leads to the following set of governing equations

$$
\begin{aligned}
& \frac{\partial(r \rho u)}{\partial z}+\frac{\partial(r \rho v)}{\partial r}=0 \\
& \frac{\partial\left(r \rho u Y_{i}\right)}{\partial z}+\frac{\partial\left(r \rho v Y_{i}\right)}{\partial r}=-\frac{\partial}{\partial r}\left(r J_{i}\right)+r \dot{\omega}_{i} W_{i} \\
& \frac{\partial\left(r \rho u^{2}\right)}{\partial z}+\frac{\partial(r \rho u v)}{\partial r}=-r \frac{\partial p}{\partial z}+\frac{\partial}{\partial r}\left(\mu r \frac{\partial u}{\partial r}\right) \\
& \frac{\partial p}{\partial r}=0 \\
& \rho=\frac{p \bar{M}}{R T}
\end{aligned}
$$

where $r$ is the radial coordinate, $\rho$ is the density, $z$ is the axial coordinate, $u$ is the axial component of velocity, $v$ is the radial component of velocity, $p$ is the pressure, $Y_{i}$ is the mass fraction of species $i, \mu$ is the viscosity, $T$ is the temperature, $J_{i}$ is the radial diffusion flux of species $i, \dot{\omega}_{i}$ is the gas-phase production rate of species $i, W_{i}$ is the molecular mass of species $k$, and $\bar{M}$ is the mean molar mass. As the simulations are carried out using isothermal conditions and the solid and gas phases consequently have the same temperature, no enthalpy balance is required. The simulations resolve the channel two-dimensionally to account for a velocity gradient due to wall effects, utilize the mean-field approximation, and treat the experiments as isothermal processes. In the mean-field approximation, the state of the reactive surface is represented by the assumed average of the states present in the evaluated computational unit, characterized by the temperature and coverages with the various species $\theta_{i}{ }^{48}$ The absolute number of actives sites and the surface area in a computational cell are linked by the surface site density $\Gamma\left(2.6 \times 10^{-5} \mathrm{~mol} \mathrm{~m}{ }^{-2}\right.$ for Ni $){ }^{49}$ This number is constant; thus, the exposed surface area of $\mathrm{Ni}$, calculated via experimental data presented in the references such as chemisorption measurements or nanoparticle size, 
Table 2. Detailed, Thermodynamically Consistent Reaction Mechanism for the Methanation of $\mathrm{CO}_{\text {and }} \mathrm{CO}_{2}$ over $\mathrm{Ni}^{a}$

\begin{tabular}{|c|c|c|c|c|}
\hline reaction & $A_{j}(\mathrm{~cm}, \mathrm{~mol}, \mathrm{~s})$ or $S_{0}(*)$ & $\beta_{j}$ & $E_{\mathrm{a}, j}\left(\mathrm{~kJ} \mathrm{~mol}^{-1}\right)$ & $\varepsilon_{i j}\left(\mathrm{~kJ} \mathrm{~mol}{ }^{-1}\right)$ \\
\hline $\mathrm{H}_{2}+2(\mathrm{~s}) \rightarrow 2 \mathrm{H}(\mathrm{s}) \quad(\mathrm{R} 1)$ & $1.46 \times 10^{-2 *}$ & 0 & 0 & \\
\hline $2 \mathrm{H}(\mathrm{s}) \rightarrow \mathrm{H}_{2}+2(\mathrm{~s}) \quad(\mathrm{R} 2)$ & $4.54 \times 10^{21}$ & -0.138 & 96.1 & \\
\hline $\mathrm{CH}_{4}+(\mathrm{s}) \rightarrow \mathrm{CH}_{4}(\mathrm{~s})$ & $1.06 \times 10^{-2 *}$ & 0 & 0 & \\
\hline $\mathrm{CH}_{4}(\mathrm{~s}) \rightarrow \mathrm{CH}_{4}+(\mathrm{s})$ & $2.79 \times 10^{15}$ & 0.085 & 37.0 & \\
\hline $\mathrm{H}_{2} \mathrm{O}+(\mathrm{s}) \rightarrow \mathrm{H}_{2} \mathrm{O}(\mathrm{s})$ & $1.16 \times 10^{-1 *}$ & 0 & 0 & \\
\hline $\mathrm{H}_{2} \mathrm{O}(\mathrm{s}) \rightarrow \mathrm{H}_{2} \mathrm{O}+(\mathrm{s})$ & $2.04 \times 10^{12}$ & -0.031 & 61.0 & \\
\hline $\mathrm{CO}_{2}+(\mathrm{s}) \rightarrow \mathrm{CO}_{2}(\mathrm{~s}) \quad(\mathrm{R} 7)$ & $6.29 \times 10^{-5 *}$ & 0 & 0 & \\
\hline $\mathrm{CO}_{2}(\mathrm{~s}) \rightarrow \mathrm{CO}_{2}+(\mathrm{s})$ & $4.99 \times 10^{7}$ & 0.018 & 25.8 & \\
\hline $\mathrm{CO}+(\mathrm{s}) \rightarrow \mathrm{CO}(\mathrm{s})$ & $3.74 \times 10^{-1 *}$ & 0 & 0 & \\
\hline $\mathrm{CO}(\mathrm{s}) \rightarrow \mathrm{CO}+(\mathrm{s}) \quad(\mathrm{R} 10)$ & $1.14 \times 10^{12}$ & -0.103 & 112.0 & $50.0^{\dagger}$ \\
\hline $\mathrm{CO}_{2}(\mathrm{~s})+(\mathrm{s}) \rightarrow \mathrm{CO}(\mathrm{s})+\mathrm{O}(\mathrm{s})$ & $1.60 \times 10^{23}$ & -1.001 & 89.3 & \\
\hline $\mathrm{CO}(\mathrm{s})+\mathrm{O}(\mathrm{s}) \rightarrow \mathrm{CO}_{2}(\mathrm{~s})+(\mathrm{s}) \quad(\mathrm{R} 12)$ & $5.81 \times 10^{19}$ & 0 & 123.6 & $50.0^{\dagger}$ \\
\hline $\mathrm{CO}(\mathrm{s})+(\mathrm{s}) \rightarrow \mathrm{C}(\mathrm{s})+\mathrm{O}(\mathrm{s}) \quad(\mathrm{R} 13)$ & $2.36 \times 10^{14}$ & 0 & 116.2 & $50.0^{\dagger}$ \\
\hline $\mathrm{C}(\mathrm{s})+\mathrm{O}(\mathrm{s}) \rightarrow \mathrm{CO}(\mathrm{s})+(\mathrm{s})$ & $2.54 \times 10^{18}$ & 0 & 148.1 & $105.0^{\ddagger}$ \\
\hline $\mathrm{CO}(\mathrm{s})+\mathrm{H}(\mathrm{s}) \rightarrow \mathrm{C}(\mathrm{s})+\mathrm{OH}(\mathrm{s}) \quad(\mathrm{R} 15)$ & $3.05 \times 10^{18}$ & -0.223 & 105.3 & $50.0^{\dagger}$ \\
\hline $\mathrm{C}(\mathrm{s})+\mathrm{OH}(\mathrm{s}) \rightarrow \mathrm{CO}(\mathrm{s})+\mathrm{H}(\mathrm{s}) \quad(\mathrm{R} 16)$ & $2.18 \times 10^{18}$ & 0.128 & 62.8 & $105.0^{\ddagger}$ \\
\hline $\mathrm{CO}(\mathrm{s})+\mathrm{H}(\mathrm{s}) \rightarrow \mathrm{HCO}(\mathrm{s})+(\mathrm{s}) \quad(\mathrm{R} 17)$ & $6.82 \times 10^{21}$ & -0.979 & 132.1 & \\
\hline $\mathrm{HCO}(\mathrm{s})+(\mathrm{s}) \rightarrow \mathrm{CO}(\mathrm{s})+\mathrm{H}(\mathrm{s}) \quad(\mathrm{R} 18)$ & $2.18 \times 10^{20}$ & -0.021 & 0.2 & $-50.0^{\dagger}$ \\
\hline $\mathrm{HCO}(\mathrm{s})+(\mathrm{s}) \rightarrow \mathrm{CH}(\mathrm{s})+\mathrm{O}(\mathrm{s})$ & $5.10 \times 10^{15}$ & 0.023 & 81.7 & \\
\hline $\mathrm{CH}(\mathrm{s})+\mathrm{O}(\mathrm{s}) \rightarrow \mathrm{HCO}(\mathrm{s})+(\mathrm{s}) \quad(\mathrm{R} 20)$ & $3.42 \times 10^{19}$ & -0.023 & 110.2 & \\
\hline $\mathrm{H}(\mathrm{s})+\mathrm{C}(\mathrm{s}) \rightarrow \mathrm{CH}(\mathrm{s})+(\mathrm{s}) \quad(\mathrm{R} 21)$ & $1.33 \times 10^{24}$ & -0.456 & 157.7 & $105.0^{\ddagger}$ \\
\hline $\mathrm{CH}(\mathrm{s})+(\mathrm{s}) \rightarrow \mathrm{C}(\mathrm{s})+\mathrm{H}(\mathrm{s}) \quad(\mathrm{R} 22)$ & $2.63 \times 10^{22}$ & 0.456 & 22.3 & \\
\hline $\mathrm{CH}(\mathrm{s})+\mathrm{H}(\mathrm{s}) \rightarrow \mathrm{CH}_{2}(\mathrm{~s})+(\mathrm{s}) \quad(\mathrm{R} 23)$ & $3.21 \times 10^{25}$ & -0.084 & 81.1 & \\
\hline $\mathrm{CH}_{2}(\mathrm{~s})+(\mathrm{s}) \rightarrow \mathrm{CH}(\mathrm{s})+\mathrm{H}(\mathrm{s})$ & $6.16 \times 10^{24}$ & 0.084 & 95.2 & \\
\hline $\mathrm{CH}_{2}(\mathrm{~s})+\mathrm{H}(\mathrm{s}) \rightarrow \mathrm{CH}_{3}(\mathrm{~s})+(\mathrm{s}) \quad(\mathrm{R} 25)$ & $7.78 \times 10^{22}$ & -0.048 & 59.5 & \\
\hline $\mathrm{CH}_{3}(\mathrm{~s})+(\mathrm{s}) \rightarrow \mathrm{CH}_{2}(\mathrm{~s})+\mathrm{H}(\mathrm{s}) \quad(\mathrm{R} 26)$ & $6.16 \times 10^{24}$ & 0.048 & 95.9 & \\
\hline $\mathrm{CH}_{3}(\mathrm{~s})+\mathrm{H}(\mathrm{s}) \rightarrow \mathrm{CH}_{4}(\mathrm{~s})+(\mathrm{s}) \quad(\mathrm{R} 27)$ & $3.63 \times 10^{21}$ & -0.048 & 65.7 & \\
\hline $\mathrm{CH}_{4}(\mathrm{~s})+(\mathrm{s}) \rightarrow \mathrm{CH}_{3}(\mathrm{~s})+\mathrm{H}(\mathrm{s}) \quad(\mathrm{R} 28)$ & $6.16 \times 10^{21}$ & 0.048 & 53.6 & \\
\hline $\mathrm{H}(\mathrm{s})+\mathrm{O}(\mathrm{s}) \rightarrow \mathrm{OH}(\mathrm{s})+(\mathrm{s})$ & $1.16 \times 10^{24}$ & -0.176 & 104.2 & \\
\hline $\mathrm{OH}(\mathrm{s})+(\mathrm{s}) \rightarrow \mathrm{H}(\mathrm{s})+\mathrm{O}(\mathrm{s})$ & $7.70 \times 10^{19}$ & 0.176 & 29.8 & \\
\hline $\mathrm{H}(\mathrm{s})+\mathrm{OH}(\mathrm{s}) \rightarrow \mathrm{H}_{2} \mathrm{O}(\mathrm{s})+(\mathrm{s}) \quad(\mathrm{R} 31)$ & $2.34 \times 10^{20}$ & 0.075 & 44.1 & \\
\hline $\mathrm{H}_{2} \mathrm{O}(\mathrm{s})+(\mathrm{s}) \rightarrow \mathrm{OH}(\mathrm{s})+\mathrm{H}(\mathrm{s}) \quad(\mathrm{R} 32)$ & $2.91 \times 10^{21}$ & -0.075 & 90.4 & \\
\hline $2 \mathrm{OH}(\mathrm{s}) \rightarrow \mathrm{H}_{2} \mathrm{O}(\mathrm{s})+\mathrm{O}(\mathrm{s})$ & $1.01 \times 10^{20}$ & 0.251 & 95.1 & \\
\hline $\mathrm{H}_{2} \mathrm{O}(\mathrm{s})+\mathrm{O}(\mathrm{s}) \rightarrow 2 \mathrm{OH}(\mathrm{s})$ & $1.89 \times 10^{25}$ & -0.251 & 215.8 & \\
\hline $\mathrm{H}(\mathrm{s})+\mathrm{CO}_{2}(\mathrm{~s}) \rightarrow \mathrm{COOH}(\mathrm{s})+(\mathrm{s}) \quad(\mathrm{R} 35)$ & $1.29 \times 10^{25}$ & -0.46 & 117.2 & \\
\hline $\mathrm{COOH}(\mathrm{s})+(\mathrm{s}) \rightarrow \mathrm{CO}_{2}(\mathrm{~s})+\mathrm{H}(\mathrm{s}) \quad(\mathrm{R} 36)$ & $1.29 \times 10^{20}$ & 0.46 & 33.8 & \\
\hline $\mathrm{COOH}(\mathrm{s})+(\mathrm{s}) \rightarrow \mathrm{CO}(\mathrm{s})+\mathrm{OH}(\mathrm{s}) \quad(\mathrm{R} 37)$ & $6.03 \times 10^{23}$ & -0.216 & 54.4 & \\
\hline $\mathrm{CO}(\mathrm{s})+\mathrm{OH}(\mathrm{s}) \rightarrow \mathrm{COOH}(\mathrm{s})+(\mathrm{s}) \quad(\mathrm{R} 38)$ & $1.45 \times 10^{21}$ & 0.216 & 97.6 & $50.0^{\dagger}$ \\
\hline $\mathrm{COOH}(\mathrm{s})+\mathrm{H}(\mathrm{s}) \rightarrow \mathrm{HCO}(\mathrm{s})+\mathrm{OH}(\mathrm{s})$ & $4.22 \times 10^{23}$ & -1.145 & 104.7 & \\
\hline $\mathrm{HCO}(\mathrm{s})+\mathrm{OH}(\mathrm{s}) \rightarrow \mathrm{COOH}(\mathrm{s})+\mathrm{H}(\mathrm{s}) \quad(\mathrm{R} 40)$ & $3.25 \times 10^{19}$ & 0.245 & 16.1 & \\
\hline $2 \mathrm{CO}(\mathrm{s}) \rightarrow \mathrm{CO}_{2}(\mathrm{~s})+\mathrm{C}(\mathrm{s}) \quad(\mathrm{R} 41)$ & $6.31 \times 10^{13}$ & 0.5 & 241.7 & $100.0^{\dagger}$ \\
\hline $\mathrm{C}(\mathrm{s})+\mathrm{CO}_{2}(\mathrm{~s}) \rightarrow 2 \mathrm{CO}(\mathrm{s})$ & $1.88 \times 10^{21}$ & -0.5 & 239.3 & $105.0^{\ddagger}$ \\
\hline
\end{tabular}

${ }^{a}(\mathrm{~s})$ represents an empty surface site. $\dagger$ denotes coverage dependency on $\mathrm{CO}(\mathrm{s}), \ddagger$ on $\mathrm{C}(\mathrm{s})$. The mechanism is available in electronic form at www. detchem.com. 


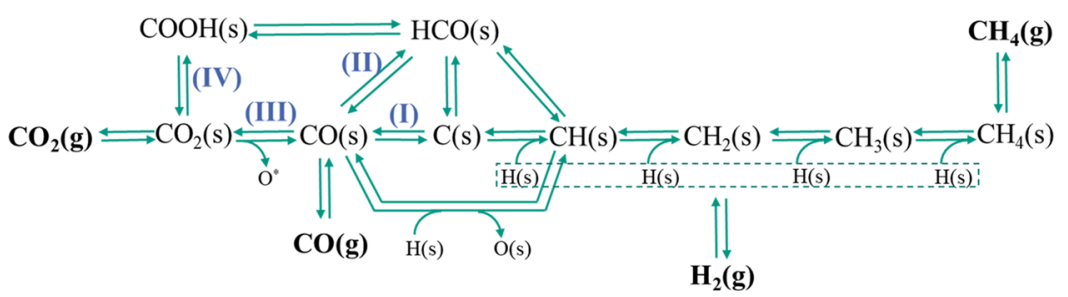

Figure 2. Reaction scheme of the kinetic model developed in this work. Some reactions are omitted for clarity. Featured pathways: (I) carbide pathway; (II) $\mathrm{H}$-assisted $\mathrm{CO}$ dissociation; (III) direct $\mathrm{CO}_{2}$ dissociation; (IV) $\mathrm{H}$-assisted $\mathrm{CO}_{2}$ dissociation.

determines the number of catalytic sites. The reaction kinetics were modeled using Arrhenius-type rate expressions of the form

$$
k_{j}=A_{j} T^{\beta_{j}} \exp \left(\frac{-E_{\mathrm{a}, j}}{R T}\right) \exp \left(\frac{\epsilon_{i j} \theta_{i j}}{R T}\right)
$$

where $k_{j}$ is the reaction rate coefficient, $A_{j}$ is the preexponential factor, $\beta_{j}$ is a temperature dependency parameter, $\theta_{i j}$ is the surface coverage of species $i$ in reaction $j, E_{\mathrm{a}, j}$ is the activation energy of reaction $j$, and $R$ is the ideal gas constant. Equation 9 accounts for coverage-dependent changes in the heat of formation of surface intermediate $i$, resulting in additional coverage-dependent contributions to the activation barrier $E_{\mathrm{a}, j}$. The corresponding contributions $\epsilon_{i j}$ are incorporated in the calculation of the activation energy according to the repulsive $\left(\epsilon_{i}>0\right)$ or attractive $\left(\epsilon_{i}<0\right)$ self-interactions of adsorbed species $i$ on the surface. However, herein, only self-interactions of the most abundant surface intermediates are considered, as those contribute the most according to the degree of rate control theory. ${ }^{50}$ The production rates of a species $\dot{s}_{i}$ are then determined by

$$
\dot{s}_{i}=\sum_{j} \nu_{j i} k_{j} \prod_{i} c_{i}^{\nu_{j i}}
$$

Here, $\nu_{j i}$ represents the stoichiometric coefficient of species $i$ in reaction $j, k_{j}$ is the reaction rate coefficient, and $c_{i}$ is the concentration of species $i$ in reaction $j$. The surface coverage of adsorbed species $\theta_{i}$ is evaluated by

$$
\frac{\partial \theta_{i}}{\partial t}=\frac{\sigma_{i} \dot{s}_{i}}{\Gamma}
$$

With $t$ representing time and $\sigma_{i}$ indicating the number of catalyst sites occupied by the adsorbate.

The software tool CaRMeN was employed as an interface between the user and the DETCHEM program package to enhance the workflow when dealing with large amounts of experiments/simulations. ${ }^{51}$ It automates sets of calculations, resulting in an accelerated workflow and a lower potential for error.

Thermodynamic consistency was enforced using the DETCHEM $^{\text {ADJUST }}$ tool. $^{45}$ It ensures that the chemical equilibrium is represented accurately for any initial composition in the limit of infinite time. To achieve this, all included reactions are required to be microkinetically reversible, i.e., every pair of forward and backward reaction rate coefficients must be linked by an equilibrium constant. With the commonly known relation between equilibrium constant and Gibbs free energy, the rate constants of a pair of forward and backward reactions $k_{\mathrm{f}}$ and $k_{\mathrm{r}}$ must fulfill the equation

$$
\frac{k_{\mathrm{f}}(T)}{k_{\mathrm{r}}(T)}=\prod_{i}\left(c_{i}^{\ominus}\right)^{\nu_{i}} \exp \left(-\frac{\Delta_{\mathrm{R}} G}{R T}\right)=F_{\mathrm{c}, \mathrm{p}} \exp \left(-\frac{\Delta_{\mathrm{R}} G}{R T}\right)
$$

with $c_{\mathrm{i}}^{\ominus}$ signifying the concentration of species $i$ at standard conditions, $\nu_{i}$ denoting the stoichiometric coefficient of $i, \Delta_{\mathrm{R}} G$ representing the Gibbs free energy of the reaction, and $F_{c, p}$ denoting the conversion factor between $K_{\mathrm{p}}$ and $K_{\mathrm{c}}$. Since the reaction Gibbs free energy is the sum of the Gibbs free energies of the partaking species, it can be expressed as

$$
\begin{aligned}
\Delta_{\mathrm{R}} G(T) & =\sum_{i} \nu_{i} G_{i}(T) \\
& =\sum_{i} \nu_{i}\left[H_{0 i}+c_{\mathrm{p} i}\left(T-T_{0}\right)-T S_{0 i}+c_{\mathrm{p} i} T \cdot \ln \frac{T}{T_{0}}\right]
\end{aligned}
$$

under the assumption of constant heat capacities. Here, $G_{i}, H_{0 i}$, $S_{0 i}$, and $\bar{c}_{\mathrm{p} i}$ represent the Gibbs free enthalpy, the standard enthalpy and entropy, and the temperature-averaged heat capacity of species $i$, respectively. Combining eq 13 with the logarithm of eq 12 yields the following relation

$$
\begin{aligned}
\ln k_{\mathrm{f}}-\ln k_{\mathrm{r}}= & \ln F_{c, \mathrm{p}}-\sum_{m} \nu_{m} \frac{G_{i}(T)}{R T}- \\
& \sum_{n} \frac{\nu_{n}}{R}\left[\frac{H_{0 n}-c_{\mathrm{p} n} T_{0}}{T}+c_{\mathrm{p} n}\left(1-\ln T_{0}\right)\right. \\
& \left.-S_{0 n}+c_{\mathrm{p} n} \ln T\right]
\end{aligned}
$$

where $m$ denotes species with known thermodynamic properties (i.e., gas-phase species) and $n$ indicates those without (i.e., surface species). Consolidating the unknown thermodynamic functions into one, $y(T)$, all known quantities into $w(T)$, and introducing the adjustments to the rate coefficients $x(T)$ yield a system of equations for the pairs of reversible reactions $q$

$$
x_{\mathrm{fq}}(T)-x_{\mathrm{rq}}(T)=w_{\mathrm{q}}(T)-\sum_{n} \nu_{n \mathrm{q}} \frac{G_{n}(T)}{R T} \cdot y_{n}(T)
$$

with

$$
w_{\mathrm{q}}(T)=\ln F_{\mathrm{c}, \mathrm{p}}-\sum_{m} \nu_{m} \frac{G_{i}(T)}{R T}-\ln k_{\mathrm{f}}+\ln k_{\mathrm{r}}
$$

and $x(T)$ and $y(T)$ in the form

$$
x_{\mathrm{q}}(T)=y_{\mathrm{n}}(T)=a+b \ln T+\frac{c}{T}
$$

The objective is to find thermodynamic functions $x_{\mathrm{q}}(T)$ and $y_{\mathrm{n}}(T)$ that fulfill eq 15 while minimizing the correction terms 

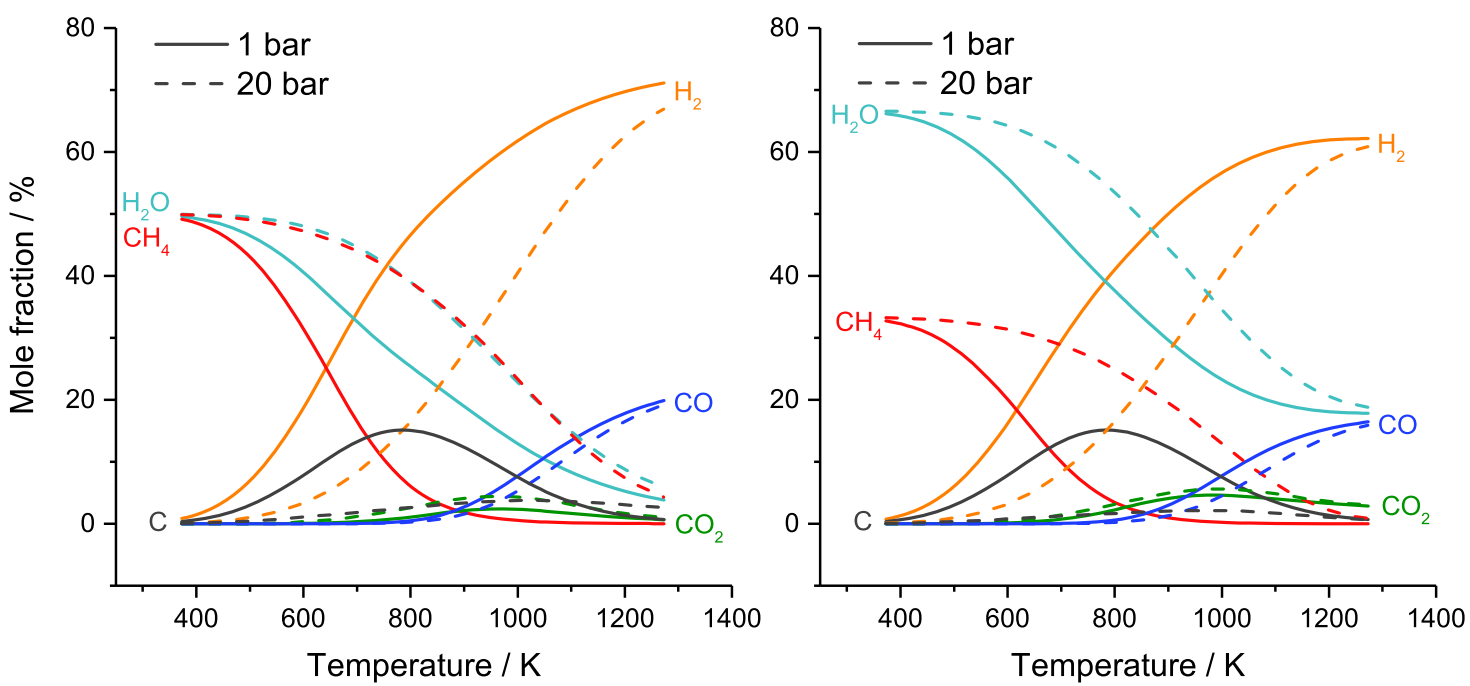

Figure 3. Equilibrium positions of stoichiometric feeds for $\mathrm{CO}$ (left, $\mathrm{H}_{2} / \mathrm{CO}=3: 1$ ) and $\mathrm{CO}_{2}$ (right, $\mathrm{H}_{2} / \mathrm{CO}_{2}=4: 1$ ) as a function of temperature for pressures of 1 (solid line) and 20 (dashed line) bar.

$x_{\mathrm{m}}(T)$. The unknown thermodynamic properties of surface species can be obtained from $y_{\mathrm{n}}(T)$. The use of DET$\mathrm{CHEM}^{\mathrm{ADJUST}}$ ensures that thermodynamic consistency is reinstated after modifications to the kinetic parameters. The adjustments to the kinetic parameters are minimized to reduce impact on the model performance. The procedure is explained in more detail in a publication by Stotz et al. ${ }^{52}$

2.3. Microkinetic Model. The presented microkinetic model is based on a model formerly developed for methane oxidation and steam reforming over $\mathrm{Ni}^{53}$ and later extended to also include $\mathrm{CO}_{2}$ reforming reactions. ${ }^{54}$ This model was not suited to emulate both $\mathrm{CO}$ and $\mathrm{CO}_{2}$ methanation reactions as well as co-methanation systems. The goal of this work is to adapt the mechanism to enable the description of all methanation reactions. The source kinetic parameters of the reversible elementary steps were derived from transition state theory and semiempirical UBI-QEP calculations for a $\mathrm{Ni}(111)$ surface in the limit of zero coverage. ${ }^{53}$ Considering the importance of carbide formation in oxygen-free methanation conditions, the selected steps with surface carbon species were corrected for $\mathrm{C}(\mathrm{s})$-coverage-dependent activation energies.

A potential energy diagram for a possible path of $\mathrm{CO}$ methanation on a $\mathrm{Ni}(111)$ surface based on heat of formation of surface intermediates and activation energies is shown in Figure 1. For the first carbon hydrogenation step, calculations for surfaces coverage $\theta_{\mathrm{C}}=0$ and $\theta_{\mathrm{C}}=1$ were performed and display a significant disparity in the activation barrier.

In the model development procedure, the preexponential factors of reactions were altered to improve the predictive quality of the model in comparison to experimental data. The changes in activation energy and the temperature parameter $\beta$ are rooted in the enforcement of thermodynamic consistency by the DETCHEM ${ }^{\text {ADJUST }}$ tool.

The surface kinetics developed in this work feature 42 elementary (forth and backward) reactions including 5 gasphase and 14 surface species. All reactions are reversible. Thermodynamic consistency is ensured between 300 and 2000 $\mathrm{K}$ by linking the reaction rate parameters of forward and backward reactions with generated equilibrium constants and thermodynamic functions. The complete detailed mechanism is presented in Table 2 .
A scheme of the kinetic model is shown in Figure 2. It includes several pathways of methane formation from both $\mathrm{CO}$ and $\mathrm{CO}_{2}$. $\mathrm{CO}$ activation is represented by a direct dissociation of adsorbed $\mathrm{CO}(\mathrm{s})$ to a surface carbide species (I) and a hydrogen-assisted dissociation, both in a single reaction step and via a formyl intermediate (II). The conversion of $\mathrm{CO}_{2}$ also features multiple pathways. The direct dissociation of $\mathrm{CO}_{2}(\mathrm{~s})$ to $\mathrm{CO}(\mathrm{s})$ (III) is included in addition to the formation of a formate/carboxyl species $\mathrm{COOH}(\mathrm{s})$ (IV), which can itself further react to $\mathrm{CO}(\mathrm{s})$ or $\mathrm{HCO}(\mathrm{s})$. The formation of $\mathrm{CH}_{4}$ is included as a result of stepwise addition of adsorbed hydrogen to $\mathrm{CH}_{x}(\mathrm{~s})(0 \leq x \leq 3)$. Water formation proceeds via a hydroxyl $(\mathrm{OH}(\mathrm{s}))$ intermediate. It is important to note that in this model, $\mathrm{C}(\mathrm{s})$ is an active intermediate species and does not block the Ni surface through coke formation.

The mechanism was developed by comparing its performance in the simulations to the experimental data and adjusting the kinetic parameters manually to improve the fit. This process was aided by reaction flow analysis and a process determining the effect of particular parameters on the predicted conversions. All major adjustments of the kinetic model were performed manually, there was no algorithmic optimization procedure. Minor changes to the model were caused by the method used to enforce thermodynamic consistency, which is described above. The performance of the mechanism is analyzed by comparing its predicted gas composition over a range of temperatures against experimental data from both literature and in-house measurements in either species axial profiles or conversion data by end-of-pipe measurements, if the former was not made available.

\section{RESULTS AND DISCUSSION}

3.1. Thermodynamic Considerations. To judge the performance of the kinetic model in the thermodynamic equilibrium, the composition of a stoichiometric feed at equilibrium as a function of temperature was evaluated using DETCHEM $^{\text {EQUIL }}{ }^{45}$ The results are displayed in Figure 3, reflecting the known fact that $\mathrm{CH}_{4}$ formation, both from $\mathrm{CO}$ and $\mathrm{CO}_{2}$, is thermodynamically suppressed by high temperatures and promoted by high pressures. At atmospheric pressure, the $\mathrm{CH}_{4}$ mole fraction in the equilibrium is very 

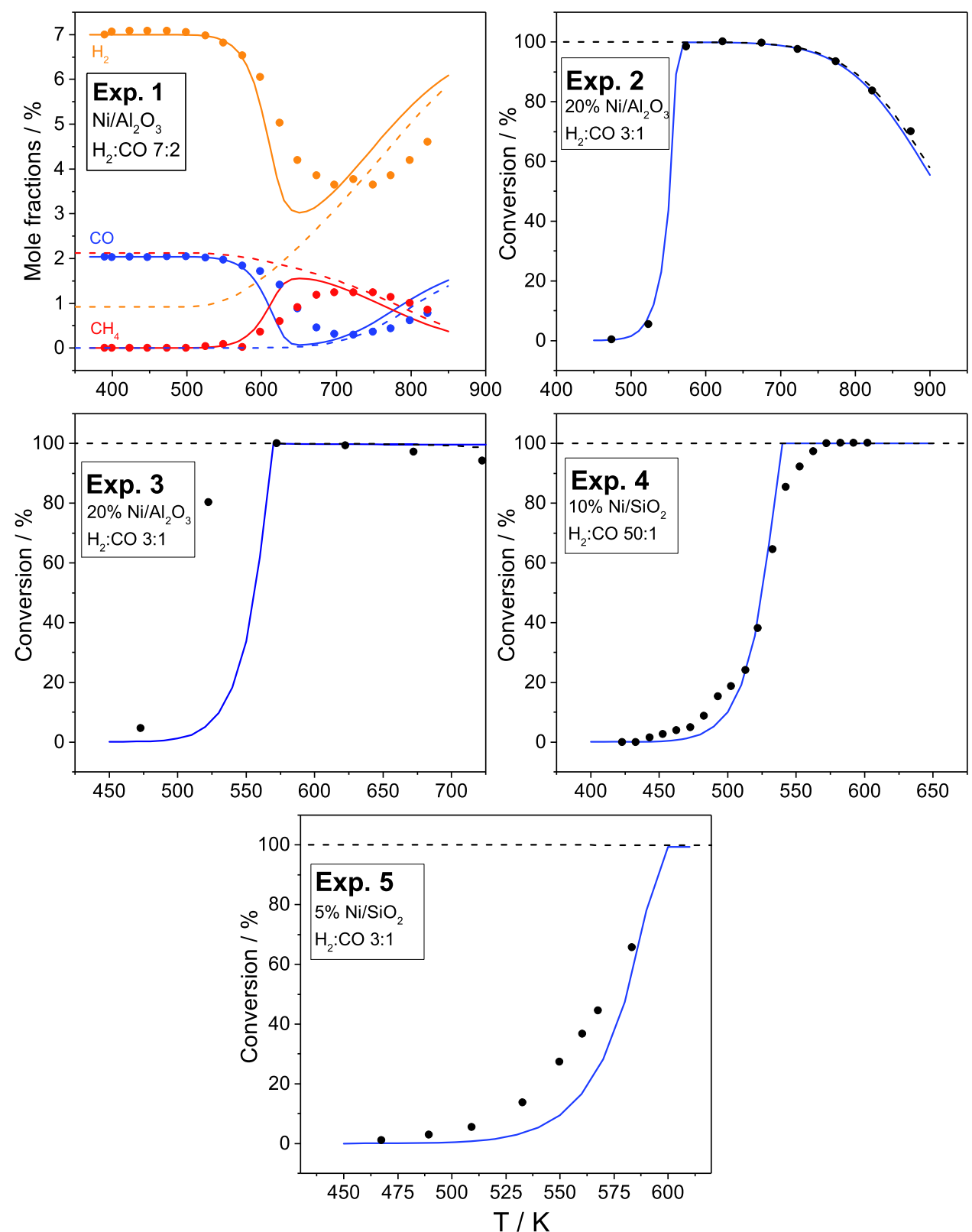

Figure 4. Comparison of simulations using the proposed kinetic model (solid lines) and the corresponding data for CO methanation experiments (points). The gas compositions/conversions at equilibrium are shown as dashed lines. The conditions belonging to the respective experiments are detailed in Table 1 .

low above $800 \mathrm{~K}$, while a significant amount is still present at even $1000 \mathrm{~K}$ for a pressure of 20 bar. Additionally, the concentration of carbon is highest at this temperature $(800 \mathrm{~K})$, which is noted for the understanding of the effect of carbon deposition on reaction kinetics (see Section 2.3). Most of the collected experiments reach equilibrium at the upper end of their temperature range; therefore, a thermodynamically consistent kinetic model is required to accurately describe the performance at all temperature ranges.

3.2. CO Methanation. The kinetic model is tested against experimental results of $\mathrm{CO}$ methanation experiments. These comparisons are shown in Figure 4. As most publications with experiments from the dataset present solely conversion data, the comparisons are restricted to this measure. Mole fraction data are used when available. For the experiments conducted in-house (experiments 1, 6, 10, and 15), the mass balances are within $1 \%$, while the other references did not cite any balances. Similarly, no data on catalyst bed temperature during experiments were provided; thus, the references were trusted by enforcing isothermal conditions in the simulations. Mass balance is enforced by the DETCHEM simulation code. The experimental conditions are listed in Table 1. Experiment 1 shows the species profiles for an experiment in a monolithic reactor with a Ni/ $\mathrm{Al}_{2} \mathrm{O}_{3}$ washcoat. ${ }^{36}$ This experiment featured a mixture of $2.04 \% \mathrm{CO}$ and $7 \% \mathrm{H}_{2}$ in $\mathrm{N}_{2}$ at 1 bar and a gas flow of $4 \mathrm{~L} \mathrm{~min}{ }^{-1}$. Experiments 2-5 show the predicted conversions against the reported experimental values for a range of experiments all performed in fixed-bed reactors. ${ }^{37-40}$ While experiments 2,3 , and 5 were carried out at a stoichiometric $\mathrm{H}_{2} / \mathrm{CO}$ ratio of $3: 1$, experiment 4 was performed with a large excess of $\mathrm{H}_{2}\left(\mathrm{H}_{2} / \mathrm{CO}=50: 1\right)$. In experiment 1 , the conversion of $\mathrm{CO}$ and $\mathrm{H}_{2}$ sets in at around 

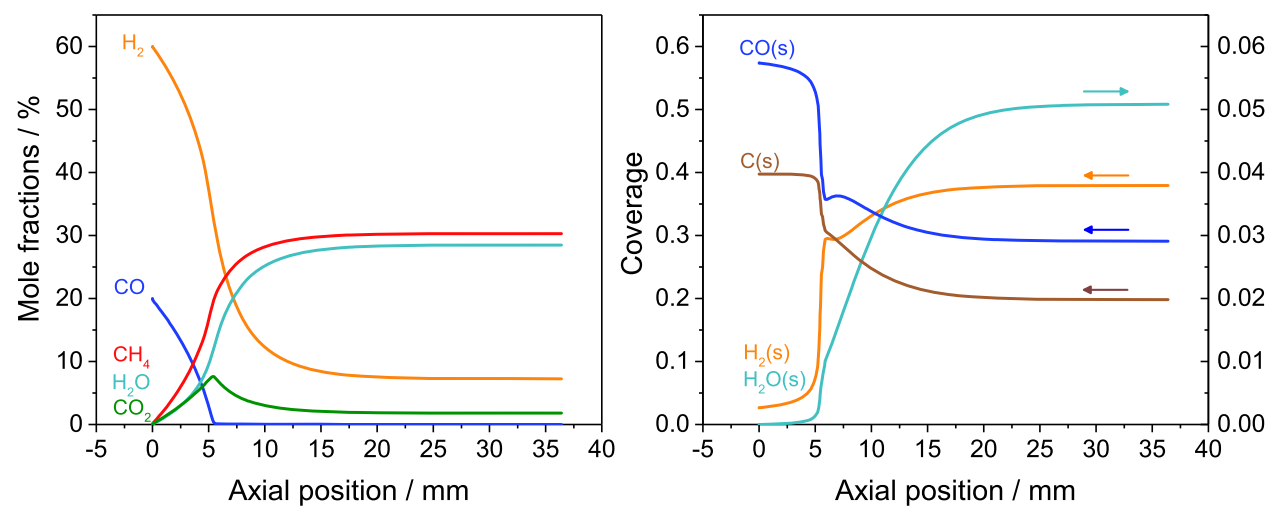

Figure 5. Gas-phase mole fractions (left) and surface coverages (right) as functions of axial reactor position predicted by the model for a CO methanation experiment with a mixture of $20 \% \mathrm{CO}, 60 \% \mathrm{H}_{2}$, and $20 \%$ inert gas over a $20 \% \mathrm{Ni} / \mathrm{Al}_{2} \mathrm{O}_{3}$ catalyst $^{37}$ (experiment 2 ) at $600 \mathrm{~K}$ at high conversion.

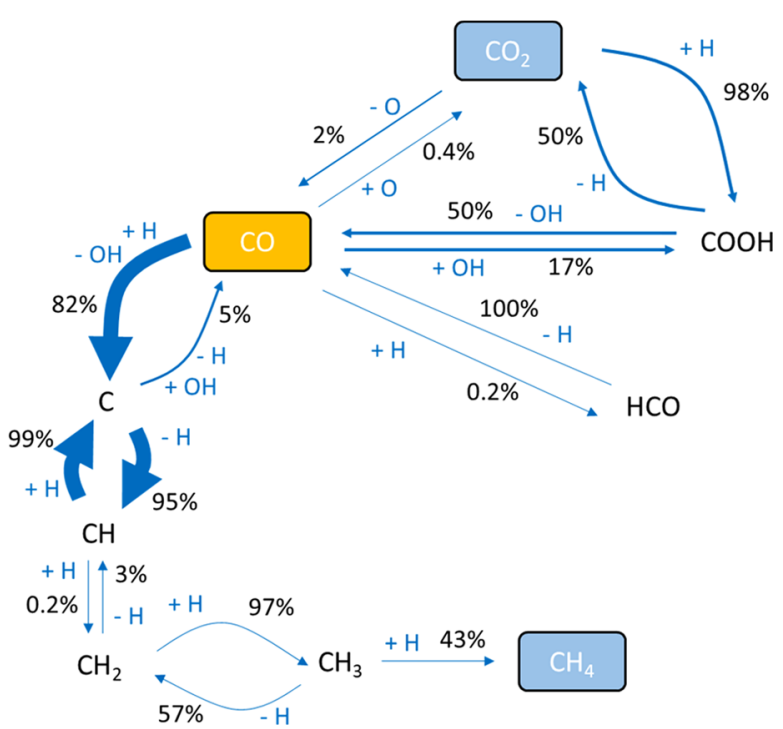

Figure 6. Reaction flow analysis for the $\mathrm{CO}$ methanation experiment $^{37}$ (experiment 2) with a mixture of $20 \% \mathrm{CO}, 60 \% \mathrm{H}_{2}$, and $20 \%$ inert gas over a $20 \% \mathrm{Ni} / \mathrm{Al}_{2} \mathrm{O}_{3}$ catalyst at $600 \mathrm{~K}$. Only surface species are shown. Reactions with proportions of less than $0.1 \%$ are omitted for ease of reading.

$550 \mathrm{~K}$. At no temperature complete conversion is achieved, at $650 \mathrm{~K}$ however, the experimental results show it coming close to it. Subsequently, thermodynamic control begins to set in and the conversion decreases, resulting in higher $\mathrm{CO}$ and $\mathrm{H}_{2}$ mole fractions at the outlet. While the kinetic model manages to reproduce the shape of the plot, it deviates in terms of matching the exact experimental values. While the simulations place the onset of the methanation reaction at a similar temperature, they overestimate the prominence of the methanation reaction at its peak at around $650 \mathrm{~K}$. For experiment 2, featuring a $20 \% \mathrm{Ni} / \mathrm{Al}_{2} \mathrm{O}_{3}$ catalyst, the agreement between simulation and experiment is very good. The light-off and emergence of equilibrium are predicted almost exactly. The predicted light-off for experiment 3, also over a $20 \% \mathrm{Ni} / \mathrm{Al}_{2} \mathrm{O}_{3}$ catalyst, occurs at a temperature that is $40 \mathrm{~K}$ higher than that of the light-off in the experiment, based on the experimental data point at $80 \%$ conversion. The results of experiment 4 , obtained for a $10 \% \mathrm{Ni} / \mathrm{SiO}_{2}$ catalyst, are also matched well by the simulations, although the equilibrium is predicted to set in slightly earlier. Similarly, the results obtained in experiment 5 with a $5 \% \mathrm{Ni} / \mathrm{SiO}_{2}$ system are approximated well, although in the intermediate-temperature range, the predicted conversions differ by up to 18 percentage points.

The reaction progression predicted by the model is shown in Figure 5. The gas-phase composition as a function of axial reactor position shows that $\mathrm{CO}$ and $\mathrm{H}_{2}$ form $\mathrm{CH}_{4}$ and $\mathrm{H}_{2} \mathrm{O}$ as per eq 1 . Additionally, $\mathrm{CO}_{2}$ is produced, presumably as a result of the Boudouard reaction. After $5 \mathrm{~mm}, \mathrm{CO}$ is completely consumed. Following this point, the generated $\mathrm{CO}_{2}$ is converted to $\mathrm{CH}_{4}$. The surface coverages show that originally, the catalyst is primarily covered with $\mathrm{CO}(\mathrm{s})$ and $\mathrm{C}(\mathrm{s})$, while after $\mathrm{CO}$ is removed from the gas phase, $\mathrm{H}(\mathrm{s})$ becomes the most abundant adsorbate. This agrees well with data about sticking coefficients of the relevant species. While the adsorption of $\mathrm{H}_{2}$ on $\mathrm{Ni}$ is less favorable than $\mathrm{CO}$, it is much more favorable than that of $\mathrm{CO}_{2}{ }^{66}$ which is reflected in the kinetic model. This leads to the change in surface coverage across the reactor. Low $\mathrm{H}(\mathrm{s})$ and high $\mathrm{CO}(\mathrm{s})$ coverages also agree well with experimental findings. ${ }^{10}$ These are interpreted by the authors to imply a low $\mathrm{C}(\mathrm{s})$ coverage due to the fast hydrogenation of carbide, which is not matched by the prediction of the presented kinetic model. Results from transient response experiments ${ }^{55}$ lead the authors to the conclusion that in $\mathrm{CO}$ methanation, the coverage with $\mathrm{C}(\mathrm{s})$ must be appreciable in addition to $\mathrm{CO}(\mathrm{s})$.

Reaction flow analysis on the simulation of a $\mathrm{CO}$ methanation experiment was performed to investigate the reaction path the model predicts for the $\mathrm{CH}_{4}$ production. The results for such an experiment ${ }^{37}$ at high conversion are displayed in Figure 6. It is apparent that the conversion of $\mathrm{CO}$ primarily is predicted to proceed via hydrogen-assisted dissociation of $\mathrm{CO}(\mathrm{s})$ and the subsequent, consecutive addition of $\mathrm{H}(\mathrm{s})$. The simulation settles on a quasi-equilibrium between $\mathrm{C}(\mathrm{s})$ and $\mathrm{CH}(\mathrm{s})$, with the second hydrogenation step representing a bottleneck for the formation of $\mathrm{CH}_{4}$.

3.3. $\mathrm{CO}_{2}$ Methanation. For the evaluation of its predictive quality in regard to $\mathrm{CO}_{2}$ methanation, the model is compared to various experimental data taken from the literature. The results are summarized in Figure 7. The RWGS reaction was studied in a monolithic (experiment 6) and a fixed-bed reactor (experiment 15; Figure S1 in the Supporting Information), where significant $\mathrm{CH}_{4}$ production was observed. ${ }^{36}$ The inlet gas for this experiment was composed of $4 \% \mathrm{CO}_{2}, 5.3 \% \mathrm{H}_{2}$, and balance $\mathrm{N}_{2}$, a higher than stoichiometric proportion of 

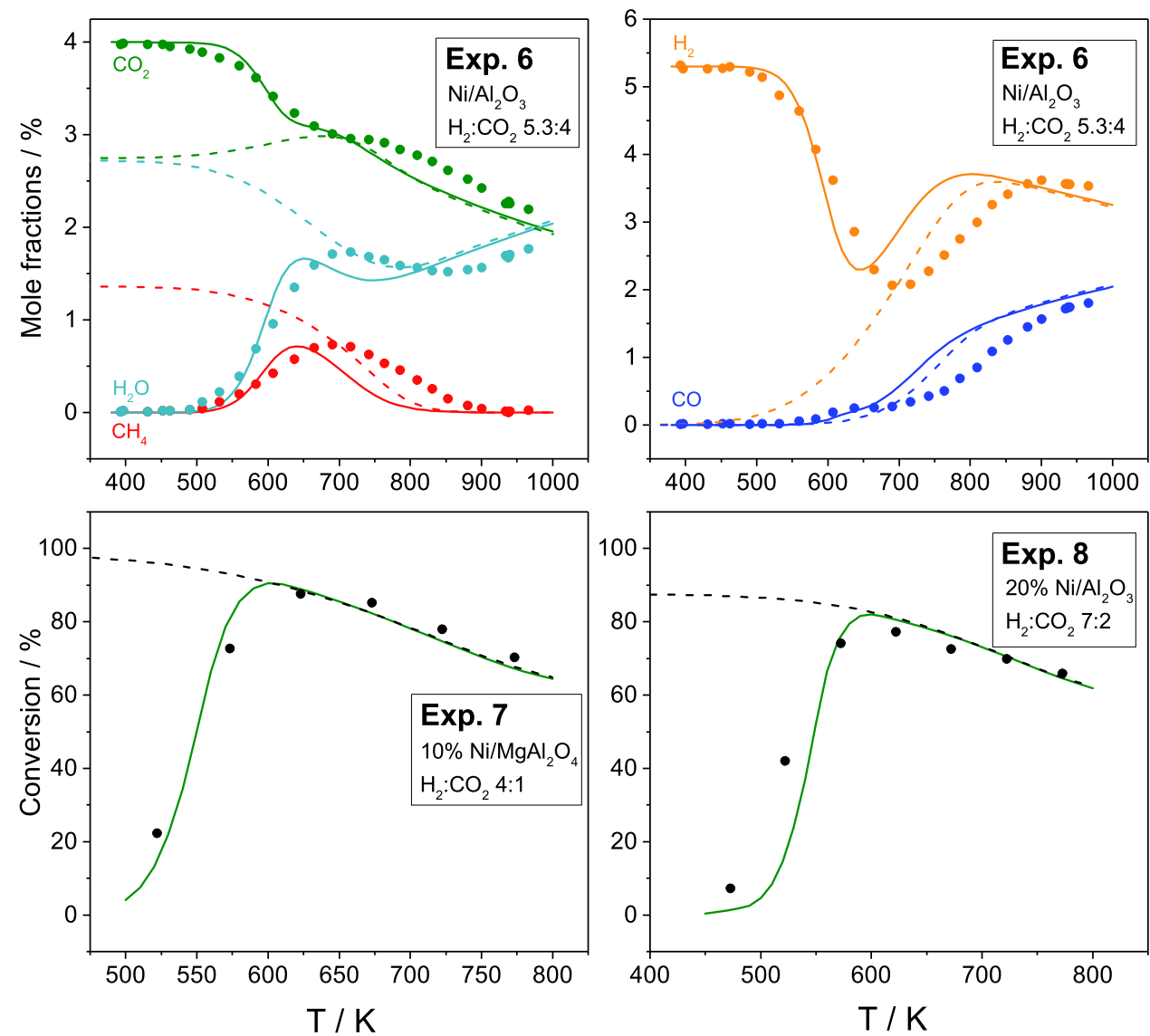

Figure 7. Comparison of simulations using the proposed kinetic model (solid lines) and the corresponding data for $\mathrm{CO}_{2}$ methanation experiments (points). The gas compositions/conversions at equilibrium are shown as dashed lines. The conditions belonging to the respective cases are detailed in Table 1.

\section{Table 3. Selection of Global Models Describing the Methanation Reactions over $\mathrm{Ni}^{a}$}

\begin{tabular}{|c|c|c|c|c|}
\hline model & reaction(s) & conditions & type & reference \\
\hline Weatherbee et al. & $\mathrm{CO}_{2}$ methanation & $1.4 \mathrm{bar}, 500-600 \mathrm{~K}$ & LHHW & 15 \\
\hline Chiang and Hopper & $\mathrm{CO}_{2}$ methanation & $7-18$ bar, $550-600 \mathrm{~K}$ & LHHW, PL & 32 \\
\hline Klose and Baerns & CO methanation & 10 bar, $453-557 \mathrm{~K}$ & LHHW & 27 \\
\hline Kai et al. & $\mathrm{CO}_{2}$ methanation & $0.4-1$ bar, $513-593 \mathrm{~K}$ & LHHW & 33 \\
\hline $\mathrm{Xu}$ and Froment & $\mathrm{CO} / \mathrm{CO}_{2}$ methanation, WGS & $3-10$ bar, $773-848 \mathrm{~K}$ & LHHW & 34 \\
\hline Koschany et al. & $\mathrm{CO}_{2}$ methanation & 8 bar, $523-613 \mathrm{~K}$ & LHHW, PL & 35 \\
\hline
\end{tabular}

${ }^{a}$ LHHW, Lindemann-Hinshelwood-Hougen-Watson Approach, PL, power law approach.

$\mathrm{CO}_{2}$ for the methanation reaction. Experiment $7^{41}$ was performed at stoichiometric reactant ratios $\left(\mathrm{H}_{2} / \mathrm{CO}_{2}=4: 1\right)$, while experiment $8^{38}$ utilized a slight $\mathrm{CO}_{2}$ excess with a $\mathrm{H}_{2}$ / $\mathrm{CO}_{2}$ ratio of 3.5. The reaction conditions are summarized in Table 1.

Compared to the results from the RWGS experiment (experiment $6^{36}$ ) over an alumina-supported catalyst, the $\mathrm{CO}_{2}$ conversion is approximated well by the model; however, the numerical results indicate a higher selectivity for the RWGS reaction than methanation at temperatures between 700 and $850 \mathrm{~K}$ compared to the experimental data. Experiments 7 and 8 , depicting experiments over a $10 \% \mathrm{Ni} / \mathrm{MgAl}_{2} \mathrm{O}_{4}$ and a $20 \%$ $\mathrm{Ni} / \mathrm{Al}_{2} \mathrm{O}_{3}$ catalyst, show good agreement between the numerical and experimental results. Discrepancies between experimental and simulated data can arise from multiple causes: as the reference dataset spans several support materials, the mechanism is affected by effects rooted in different supports. As described above, there is some evidence for a change in the reaction pathway on different supports. Due to the possibility of significant activity occurring on the surface of basic support materials such as $\mathrm{Y}_{2} \mathrm{O}_{3}$ and $\mathrm{CeO}_{2}$, experiments on these materials have not been included in the dataset and more inert supports such as $\mathrm{TiO}_{2}$ and $\mathrm{Al}_{2} \mathrm{O}_{3}$ are featured prominently. The support effects, especially concerning the respective mechanism expected on the respective material, must be considered when applying the kinetic model. Another possible reason for this is the assumption of isothermal conditions in the simulation. While some experiments in the dataset make use of dilution of both the reactant gases and the catalyst, the heat of reaction in the others must not be neglected. As $\mathrm{CO}$ and $\mathrm{CO}_{2}$ methanation are exothermic processes, the actual temperature inside the catalyst may be higher than the externally measured one. In some experiments, reactant gases are not diluted, which may lead to hotspot formation during the experiment. The higher temperature 


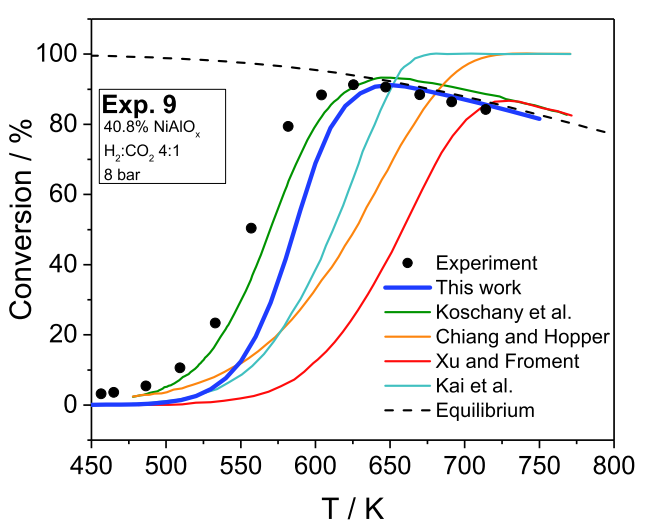

Figure 8. Comparison of the predicted conversions for a $\mathrm{CO}_{2}$ methanation experiment ${ }^{35}$ for the detailed kinetic model (blue) and a sample of global models. The experimental values are represented as dots, and the equilibrium compositions are indicated by the dashed line.

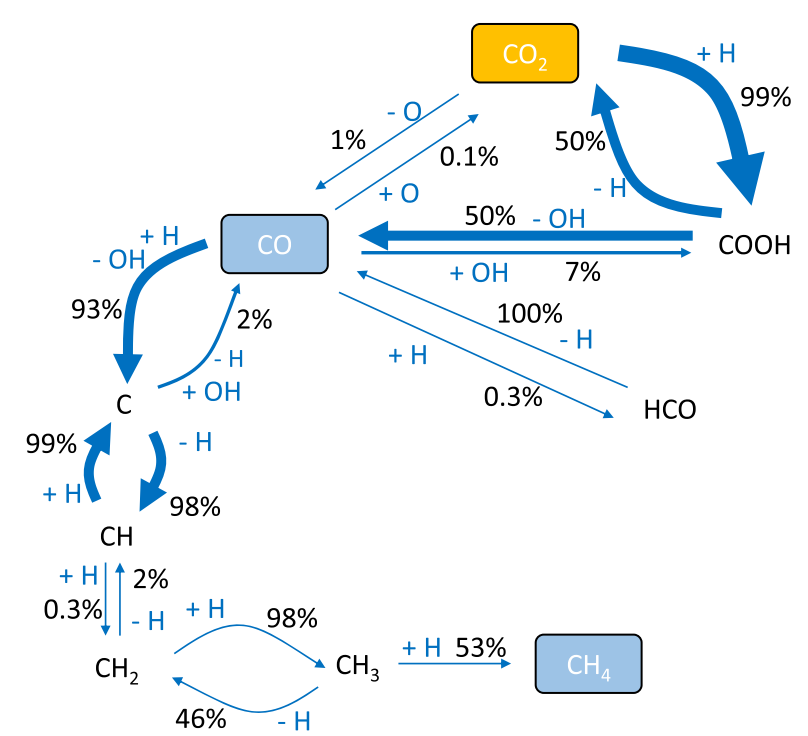

Figure 9. Reaction flow analysis for a $\mathrm{CO}_{2}$ methanation experiment with a gas mixture of $10 \% \mathrm{CO}_{2}$ and $40 \% \mathrm{H}_{2}$ with $50 \%$ inert gas over a $40.8 \% \mathrm{NiAlO}_{x}$ catalyst at $600 \mathrm{~K}$ (experiment $9^{35}$ ). Only surface species are shown. Reactions with proportions of less than $0.1 \%$ are omitted for ease of reading.

might suppress the exothermic methanation reaction, leading to an overestimation by the simulation.

Additionally, the model was compared to global kinetics for an experiment over a $40.8 \% \mathrm{NiAlO}_{x}$ catalyst at a pressure of 8 bar (experiment 9). ${ }^{35}$ A selection of global models is listed in Table 3. The rate expressions of the listed models are included in Table S1 in the Supporting Information. The comparison, presented in Figure 8, shows that for this experiment, our kinetic model matches the experimental data more accurately than any of the global models except the one presented in the original publication, itself derived with this experiment as part of the dataset. The latter agrees better with the experimental data at lower temperatures, while the equilibrium is better represented by the model presented herein. A clear advantage of detailed kinetics is also immediately apparent in the description of the equilibrium composition. Two of the represented global models only contain a term for the forward reaction, which leads to the prediction of full conversions at higher temperatures and absence of an equilibrium. Due to the nature of thermodynamically consistent elementary kinetic models, the correct representation of the equilibrium is ensured. It is also important to note that this experiment was performed at a pressure of 8 bar. Despite the dataset used to establish this kinetic model consisting almost exclusively of experiments at atmospheric pressure, this result shows that the mechanism can successfully be applied to higher pressures.

To gain further information on the mechanism of the methanation reaction, its reaction pathway has been evaluated using reaction flow analysis of the simulations. The results for a $\mathrm{CO}_{2}$ methanation study (experiment $9^{35}$ ) are displayed in Figure 9.

The analysis shows that using this kinetic model, the methanation is predicted to proceed largely via the direct hydrogenation of $\mathrm{CO}_{2}(\mathrm{~s})$ and the dissociation of the resulting formate intermediate to form $\mathrm{CO}(\mathrm{s})$, which consequently forms the surface carbide $\mathrm{C}(\mathrm{s})$ by the way of $\mathrm{H}$-assisted dissociation. This last step is anticipated to proceed directly, without the formation of a formyl intermediate. The prominence of the formate/carboxyl intermediate is supported by in situ measurements ${ }^{17,22}$ as well as DFT calculations that conclude that direct hydrogenation of $\mathrm{CO}_{2}(\mathrm{~s})$ is more favorable than direct dissociation. ${ }^{19}$ As the simulations predict the dissociation of formate into $\mathrm{CO}(\mathrm{s})$, experimental results that show $\mathrm{CO}(\mathrm{s})$ as an intermediate ${ }^{16,56,57}$ are not in disagreement with the numerical results. DFT calculations by different groups show that the direct dissociation should however be favored energetically. ${ }^{18,31}$ More research into the mechanism of $\mathrm{CO}_{2}$ methanation is therefore recommended.

3.4. Combined $\mathrm{CO}$ and $\mathrm{CO}_{2}$ Methanation. The applicability of the model in regard to methanation using both $\mathrm{CO}$ and $\mathrm{CO}_{2}$ in the inlet gas is discussed next. This reaction system often exhibits an inhibition of $\mathrm{CO}_{2}$ conversion in the presence of amounts of $\mathrm{CO}$ as small as $200 \mathrm{ppm}^{6}$ Therefore, in hydrogenation experiments of $\mathrm{CO}$ and $\mathrm{CO}_{2}, \mathrm{CO}_{2}$ conversion only sets in after $\mathrm{CO}$ is almost completely converted. $^{42,44}$ Two such experiments are displayed in Figure 10. Experiment 10 features an experiment converting a mixture of $35.5 \% \mathrm{H}_{2}, 17.6 \% \mathrm{CO}_{2}, 11.8 \% \mathrm{CO}, 4.1 \% \mathrm{CH}_{4}$, and $59 \mathrm{ppm}$ $\mathrm{O}_{2}$ over a $\mathrm{Ni} / \mathrm{Al}_{2} \mathrm{O}_{3}$ catalyst. $^{36}$ Interestingly, at this initial composition, $\mathrm{CO}_{2}$ is not converted into $\mathrm{CH}_{4}$, but rather produced, especially at temperatures above $500 \mathrm{~K}$. The model predicts this behavior well. In experiment 11, there is significant conversion of both $\mathrm{CO}$ and $\mathrm{CO}_{2}$. In the study over a $5 \% \mathrm{Ni} / \mathrm{ZrO}_{2}$ catalyst with an inlet gas composition of $17 \% \mathrm{CO}_{2}, 57 \% \mathrm{H}_{2}$, and $0.6 \% \mathrm{CO}$, the predicted light-off of $\mathrm{CO}$ and $\mathrm{CO}_{2}$ occurs up to $30 \mathrm{~K}$ sooner than that observed in the experiment. Both the experimental and simulation data clearly depict the inhibition of $\mathrm{CO}_{2}$ methanation by the presence of CO. At lower temperatures, $\mathrm{CO}$ is converted to $\mathrm{CH}_{4}$ and $\mathrm{H}_{2} \mathrm{O}$, with conversion increasing with rising temperatures. Once a large portion of $\mathrm{CO}$ is consumed, $\mathrm{CO}_{2}$ conversion sets in. At the beginning, $\mathrm{CO}_{2}$ is partially converted to $\mathrm{CO}$ (this leads to the return of negative conversion values of $\mathrm{CO}$ ), which is further fully hydrogenated to $\mathrm{CH}_{4}$. This phenomenon is replicated well by the model, although both $\mathrm{CO}$ and $\mathrm{CO}_{2}$ conversions are predicted to occur at higher temperatures than the experiment shows.

To illustrate this phenomenon more clearly, the simulated progression of the reactive flow through the catalyst bed in another co-methanation experiment over a $5 \% \mathrm{Ni} / \mathrm{SiO}_{2}$ catalyst (experiment $18 ;^{44}$ conversion graph in Figure $\mathrm{S} 2$ in 


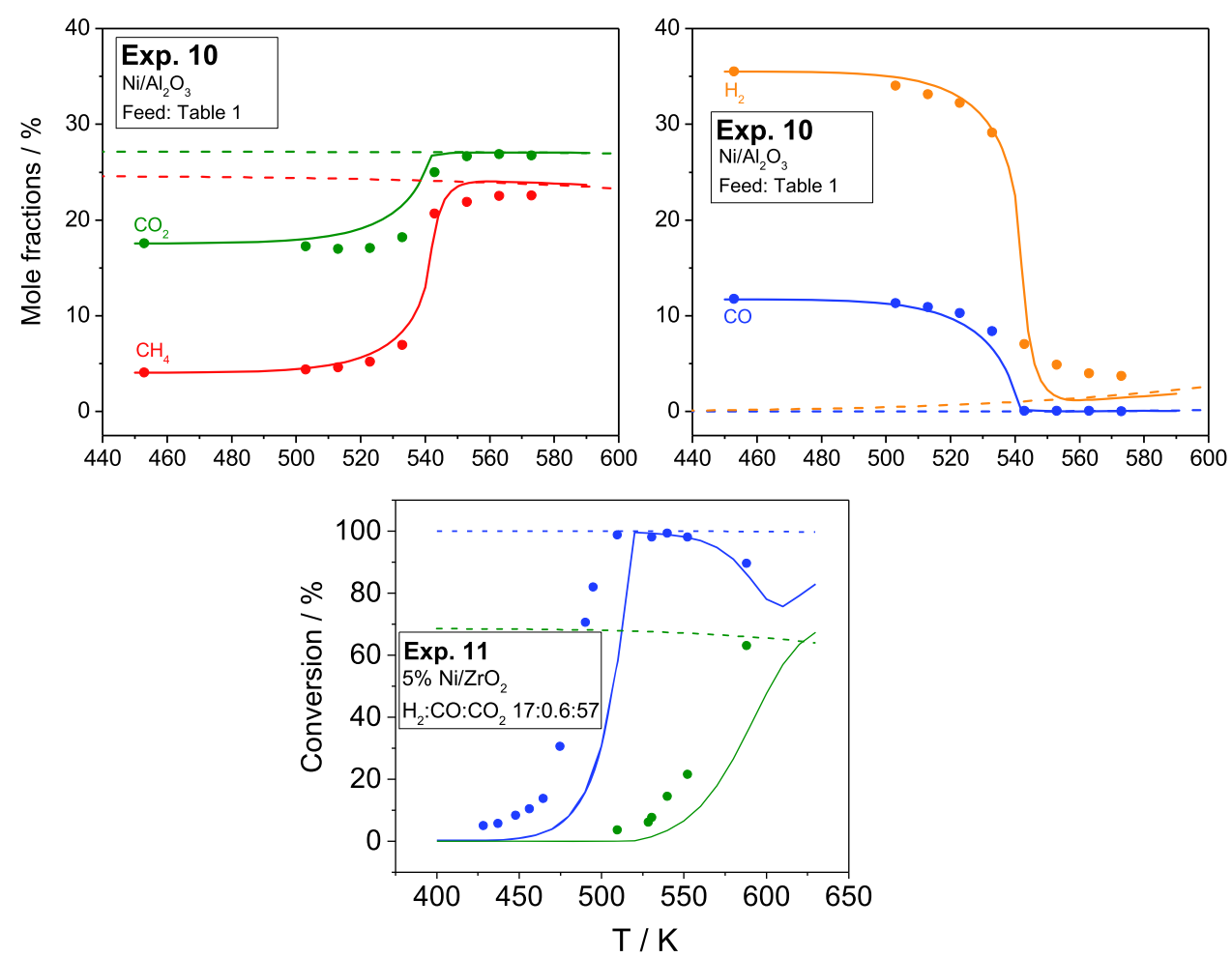

Figure 10. Comparison of numerical simulation results using the featured kinetic model (solid lines) to the corresponding experimental results (points) for experiments whose inlet gas contains both $\mathrm{CO}$ and $\mathrm{CO}_{2}$. Thermodynamic equilibrium is shown as dashed lines. The experimental conditions are detailed in Table 1.
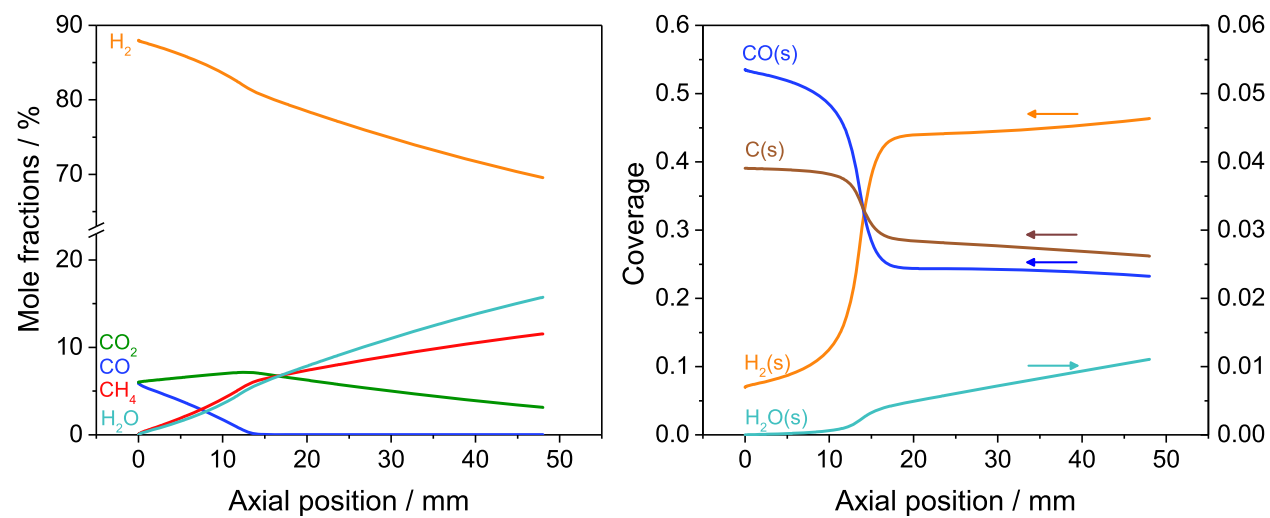

Figure 11. Gas-phase composition (left) and surface coverages (right) as functions of axial reactor position as predicted by the simulation of comethanation with the mixture of $6 \% \mathrm{CO}_{2}, 6 \% \mathrm{CO}$, and $88 \% \mathrm{H}_{2}$ over a $5 \% \mathrm{Ni} / \mathrm{SiO}_{2}$ catalyst at $600 \mathrm{~K}$ (experiment $18^{44}$ ).

the Supporting Information) at $600 \mathrm{~K}$ is displayed in Figure 11. The gas-phase composition shows that despite the presence of the same amount of $\mathrm{CO}_{2}$ initially, it is only converted after $\mathrm{CO}$ is completely consumed. In comparison to Figure 5 , it is also notable that the selectivity toward the methanation reaction as opposed to the competing WGS and Boudouard reactions is higher due to the presence of $\mathrm{CO}_{2}$. Similarly to $\mathrm{CO}$ methanation, $\mathrm{H}(\mathrm{s})$ coverage increases after the transition from $\mathrm{CO}$ to $\mathrm{CO}_{2}$ methanation, while $\mathrm{CO}(\mathrm{s})$ and $\mathrm{C}(\mathrm{s})$ cover less of the $\mathrm{Ni}$ sites.

Generally, the replication of the experiments, i.e., the conversion from experimental parameters to physical input data for the simulations in this work is affected by uncertainties that may be the cause for deviations between experimental and simulated data. As not all publications listed all necessary parameters, some needed to be approximated. As an example, the number of available catalytic sites was calculated based on the size of the Ni particles if no specific surface area was given.

\section{CONCLUSIONS}

A detailed model for the surface kinetics of $\mathrm{CO}$ and $\mathrm{CO}_{2}$ methanation over nickel-based catalysts was developed. It is the first of its kind to model both methanation reactions while being thermodynamically consistent. Previously published models either consist of global kinetics or lacked steps necessary for the description of both methanation reactions. Kinetic parameters of the proposed microkinetic model were based on theoretical estimations and fine-tuned to match a wide variety of datasets from both in-house and literature studies with different $\mathrm{Ni}$ catalysts at a wide range of operating conditions. The thermodynamic consistency of the model was always ensured in this development process. The computa- 
tional results show that the presence of surface carbide plays a significant role in $\mathrm{CO}$ hydrogenation and that the formate pathway is favored for the methanation of $\mathrm{CO}_{2}$.

The developed model is able to describe the various processes $\left(\mathrm{CO}, \mathrm{CO}_{2}\right.$, and co-methanation) reasonably well and is thus suitable to be implemented for explorative studies concerning methanation. Therefore, the model can assist in the evaluation and optimization of reactor performance for research and technical purposes. The kinetic model can be easily implemented in standard chemical software packages such as CHEMKIN, ${ }^{58,59}$ CANTERA, $^{60}$ and DETCHEM, ${ }^{45}$ and is available electronically (Supporting Information; www. detchem.com/mechanisms). This model is specifically adapted for methanation systems, but has performed well in simulations of a set of steam methane-reforming reactions ${ }^{61}$ when applied. One such result is shown in Figure S3 in the Supporting Information. However, published models explicitly designed for these reactions of the $\mathrm{CO}_{2} / \mathrm{CO} / \mathrm{H}_{2} / \mathrm{H}_{2} \mathrm{O} / \mathrm{CH}_{4}{ }^{53,54}$ system are recommended for use.

The model was purposely not developed for a specific support by including data from various catalyst/support systems and from a wide range of conditions, and thus tests for a variety of materials. Based on our experience, the model can be adapted for other supports or to better match the kinetics of one specific support by fine-tuning the kinetic data, of course under the assumption that no new reaction paths need to be added due to a difference in the assumed mechanism. The modification for additional temperature effects on support contributions is similarly possible. Furthermore, the model may be extended with steps for the formation of surface-blocking coke to reproduce deactivation effects observed on Ni catalysts. Thermodynamic consistency needs to be ensured in this adaption of kinetic data. In this sense, the microkinetic scheme derived becomes a very helpful tool for scale-up, reactor, and process simulations. Because of the limited information available in the literature references, no detailed error analysis was possible for the presented experiments. In future investigations, including error estimates with experimental data is recommended to aid model development. In addition to further research into the effect of the support materials, we recommend additional investigations of the methanation systems under conditions of carbon oxide excess and especially at higher pressures, which are commonly utilized in larger-scale methanation processes.

\section{ASSOCIATED CONTENT}

\section{SI Supporting Information}

The Supporting Information is available free of charge at https://pubs.acs.org/doi/10.1021/acs.iecr.1c00389.

Comparison of simulated and experimental data for remaining methanation experiments, omitted for brevity; list of global kinetic models for the description of methanation reactions; and performance of model for methane steam reforming (PDF)

\section{AUTHOR INFORMATION}

\section{Corresponding Author}

Olaf Deutschmann - Institute for Chemical Technology and Polymer Chemistry, Karlsruhe Institute of Technology, D76131 Karlsruhe, Germany; Institute for Catalysis Research and Technology, Karlsruhe Institute of Technology, D-76131
Karlsruhe, Germany; 이이이.org/0000-0001-9211-7529; Email: deutschmann@kit.edu

\section{Authors}

Daniel Schmider - Institute for Chemical Technology and Polymer Chemistry, Karlsruhe Institute of Technology, D76131 Karlsruhe, Germany

Lubow Maier - Institute for Catalysis Research and Technology, Karlsruhe Institute of Technology, D-76131 Karlsruhe, Germany

Complete contact information is available at: https://pubs.acs.org/10.1021/acs.iecr.1c00389

\section{Notes}

The authors declare no competing financial interest.

\section{ACKNOWLEDGMENTS}

The authors acknowledge Steinbeis Transferzentrum 240 Reaktive Strömung of the Steinbeis $\mathrm{GmbH} \&$ Co. KG für Technologietransfer and omegadot software \& consulting $\mathrm{GmbH}$ for providing cost-free license of the software tools DETCHEM and CaRMeN, respectively. This work was partially conducted within the NFDI4Cat initiative funded by the Deutsche Forschungsgemeinschaft (DFG, German Research Foundation) with project number 670389-NFDI 2/ 1 .

\section{REFERENCES}

(1) Vrijburg, W. L.; Moioli, E.; Chen, W.; Zhang, M.; Terlingen, B. J. P.; Zijlstra, B.; Filot, I. A. W.; Züttel, A.; Pidko, E. A.; Hensen, E. J. M. Efficient Base-Metal NiMn/TiO 2 Catalyst for $\mathrm{CO}_{2}$ Methanation. ACS Catal. 2019, 9, 7823-7839.

(2) Menon, V.; Janardhanan, V. M.; Deutschmann, O. A mathematical model to analyze solid oxide electrolyzer cells (SOECs) for hydrogen production. Chem. Eng. Sci. 2014, 110, 83-93.

(3) Uribe-Soto, W.; Portha, J.-F.; Commenge, J.-M.; Falk, L. A review of thermochemical processes and technologies to use steelworks off-gases. Renewable Sustainable Energy Rev. 2017, 74, 809-823.

(4) Sabatier, P.; Senderens, J. Direct hydrogenation of oxides of carbon in presence of various finely divided metals. C. R. Acad. Sci. 1902, 134, 689-691.

(5) Jalama, K. Carbon dioxide hydrogenation over nickel-, ruthenium-, and copper-based catalysts: Review of kinetics and mechanism. Catal. Rev. 2017, 59, 95-164.

(6) Rönsch, S.; Schneider, J.; Matthischke, S.; Schlüter, M.; Götz, M.; Lefebvre, J.; Prabhakaran, P.; Bajohr, S. Review on methanation From fundamentals to current projects. Fuel 2016, 166, 276-296.

(7) Stangeland, K.; Kalai, D.; Li, H.; Yu, Z. $\mathrm{CO}_{2}$ Methanation: The Effect of Catalysts and Reaction Conditions. Energy Procedia 2017, 105, 2022-2027.

(8) Vogt, C.; Monai, M.; Kramer, G. J.; Weckhuysen, B. M. The renaissance of the Sabatier reaction and its applications on Earth and in space. Nat. Catal. 2019, 2, 188-197.

(9) Gardner, D. C.; Bartholomew, C. H. Kinetics of carbon deposition during methanation of carbon monoxide. Ind. Eng. Chem. Prod. Res. Dev. 1981, 20, 80-87.

(10) Sehested, J.; Dahl, S.; Jacobsen, J.; Rostrup-Nielsen, J. R. Methanation of CO over Nickel: Mechanism and Kinetics at High $\mathrm{H}_{2} /$ CO Ratios. J. Phys. Chem. B 2005, 109, 2432-2438.

(11) Goodwan, D. W.; Kelley, R. D.; Madey, T. E.; White, J. M. Measurement of carbide buildup and removal kinetics on $\mathrm{Ni}(100)$. J. Catal. 1980, 64, 479-481.

(12) Hayes, R. E.; Thomas, W. J.; Hayes, K. E. A study of the nickelcatalyzed methanation reaction. J. Catal. 1985, 92, 312-326. 
(13) Wentrcek, P. R.; Wood, B. J.; Wise, H. The role of surface carbon in catalytic methanation. J. Catal. 1976, 43, 363-366.

(14) Alstrup, I. On the Kinetics of Co Methanation on Nickel Surfaces. J. Catal. 1995, 151, 216-225.

(15) Weatherbee, G.; Bartholomew, C. H. Hydrogenation of $\mathrm{CO}_{2}$ on group VIII metals II. Kinetics and mechanism of $\mathrm{CO}_{2}$ hydrogenation on nickel. J. Catal. 1982, 77, 460-472.

(16) Osaki, T.; Mori, T. Kinetic studies of CO2dissociation on supported Ni catalysts. React. Kinet. Catal. Lett. 2005, 87, 149-156.

(17) Schild, C.; Wokaun, A.; Koeppel, R. A.; Baiker, A. Carbon dioxide hydrogenation over nickel/zirconia catalysts from amorphous precursors: on the mechanism of methane formation. J. Phys. Chem. A 1991, 95, 6341-6346.

(18) Ren, J.; Guo, H.; Yang, J.; Qin, Z.; Lin, J.; Li, Z. Insights into the mechanisms of $\mathrm{CO}_{2}$ methanation on $\mathrm{Ni}(111)$ surfaces by density functional theory. Appl. Surf. Sci. 2015, 351, 504-516.

(19) Vesselli, E.; De Rogatis, L.; Ding, X.; Baraldi, A.; Savio, L.; Vattuone, L.; Rocca, M.; Fornasiero, P.; Peressi, M.; Baldereschi, A.; Rosei, R.; Comelli, G. Carbon Dioxide Hydrogenation on $\mathrm{Ni}(110)$. J. Am. Chem. Soc. 2008, 130, 11417-11422.

(20) de Carvalho, T. P.; Catapan, R. C.; Oliveira, A. A. M.; Vlachos, D. G. Microkinetic Modeling and Reduced Rate Expression of the Water-Gas Shift Reaction on Nickel. Ind. Eng. Chem. Res. 2018, 57, 10269-10280.

(21) Shen, L.; Xu, J.; Zhu, M.; Han, Y.-F. Essential Role of the Support for Nickel-Based $\mathrm{CO}_{2}$ Methanation Catalysts. ACS Catal. 2020, 14581-14591.

(22) Aldana, P. A. U.; Ocampo, F.; Kobl, K.; Louis, B.; ThibaultStarzyk, F.; Daturi, M.; Bazin, P.; Thomas, S.; Roger, A. C. Catalytic $\mathrm{CO}_{2}$ valorization into $\mathrm{CH}_{4}$ on Ni-based ceria-zirconia. Reaction mechanism by operando IR spectroscopy. Catal. Today 2013, 215, 201-207.

(23) Zhang, Z.; Tian, Y.; Zhang, L.; Hu, S.; Xiang, J.; Wang, Y.; Xu, L.; Liu, Q.; Zhang, S.; Hu, X. Impacts of nickel loading on properties, catalytic behaviors of $\mathrm{Ni} / \gamma-\mathrm{Al}_{2} \mathrm{O}_{3}$ catalysts and the reaction intermediates formed in methanation of $\mathrm{CO}_{2}$. Int. J. Hydrogen Energy 2019, 44, 9291-9306.

(24) Fatah, N. A. A.; Jalil, A. A.; Salleh, N. F. M.; Hamid, M. Y. S.; Hassan, Z. H.; Nawawi, M. G. M. Elucidation of cobalt disturbance on $\mathrm{Ni} / \mathrm{Al}_{2} \mathrm{O}_{3}$ in dissociating hydrogen towards improved $\mathrm{CO}_{2}$ methanation and optimization by response surface methodology (RSM). Int. J. Hydrogen Energy 2020, 45, 18562-18573.

(25) Muroyama, H.; Tsuda, Y.; Asakoshi, T.; Masitah, H.; Okanishi, T.; Matsui, T.; Eguchi, K. Carbon dioxide methanation over $\mathrm{Ni}$ catalysts supported on various metal oxides. J. Catal. 2016, 343, 178184.

(26) Ye, R.-P.; Li, Q.; Gong, W.; Wang, T.; Razink, J. J.; Lin, L.; Qin, Y.-Y.; Zhou, Z.; Adidharma, H.; Tang, J.; Russell, A. G.; Fan, M.; Yao, Y.-G. High-performance of nanostructured $\mathrm{Ni} / \mathrm{CeO}_{2}$ catalyst on $\mathrm{CO}_{2}$ methanation. Appl. Catal., B 2020, 268, No. 118474.

(27) Klose, J.; Baerns, M. Kinetics of the methanation of carbon monoxide on an alumina-supported nickel catalyst. J. Catal. 1984, 85, $105-116$.

(28) Medsforth, S. Promotion of catalytic reactions. Part I. J. Chem. Soc., Trans. 1923, 123, 1452-1469.

(29) Vesselli, E.; Rizzi, M.; De Rogatis, L.; Ding, X.; Baraldi, A.; Comelli, G.; Savio, L.; Vattuone, L.; Rocca, M.; Fornasiero, P.; Baldereschi, A.; Peressi, M. Hydrogen-Assisted Transformation of $\mathrm{CO}_{2}$ on Nickel: The Role of Formate and Carbon Monoxide. J. Phys. Chem. Lett. 2010, 1, 402-406.

(30) Vlasenko, V. M.; Yuzefovich, G. E. Mechanism of the Catalytic Hydrogenation of Oxides of Carbon to Methane. Russ. Chem. Rev. 1969, 38, No. 728.

(31) Vogt, C.; Monai, M.; Sterk, E. B.; Palle, J.; Melcherts, A. E. M.; Zijlstra, B.; Groeneveld, E.; Berben, P. H.; Boereboom, J. M.; Hensen, E. J. M.; Meirer, F.; Filot, I. A. W.; Weckhuysen, B. M. Understanding carbon dioxide activation and carbon-carbon coupling over nickel. Nat. Commun. 2019, 10, No. 5330.
(32) Chiang, J. H.; Hopper, J. R. Kinetics of the hydrogenation of carbon dioxide over supported nickel. Ind. Eng. Chem. Prod. Res. Dev. 1983, 22, 225-228.

(33) Kai, T.; Takahashi, T.; Furusaki, S. Kinetics of the methanation of carbon dioxide over a supported $\mathrm{Ni}-\mathrm{La}_{2} \mathrm{O}_{3}$ catalyst. Can. J. Chem. Eng. 1988, 66, 343-347.

(34) Xu, J.; Froment, G. F. Methane steam reforming, methanation and water-gas shift: I. Intrinsic kinetics. AlChE J. 1989, 35, 88-96.

(35) Koschany, F.; Schlereth, D.; Hinrichsen, O. On the kinetics of the methanation of carbon dioxide on coprecipitated $\mathrm{NiAl}(\mathrm{O})_{\mathrm{x}}$. Appl. Catal., B 2016, 181, 504-516.

(36) Herrera Delgado, K. Surface Reaction Kinetics for Oxidation and Reforming of $\mathrm{H}_{2}, \mathrm{CO}$, and $\mathrm{CH}_{4}$ over Nickel-based Catalysts. Doctoral Dissertation, Karlsruher Institut für Technologie: Karlsruhe, 2014.

(37) Hu, D.; Gao, J.; Ping, Y.; Jia, L.; Gunawan, P.; Zhong, Z.; Xu, G.; Gu, F.; Su, F. Enhanced Investigation of $\mathrm{CO}$ Methanation over $\mathrm{Ni} / \mathrm{Al}_{2} \mathrm{O}_{3}$ Catalysts for Synthetic Natural Gas Production. Ind. Eng. Chem. Res. 2012, 51, 4875-4886.

(38) Rahmani, S.; Rezaei, M.; Meshkani, F. Preparation of promoted nickel catalysts supported on mesoporous nanocrystalline gamma alumina for carbon dioxide methanation reaction. J. Ind. Eng. Chem. 2014, 20, 4176-4182.

(39) Le, T. A.; Kim, M. S.; Lee, S. H.; Kim, T. W.; Park, E. D. CO and $\mathrm{CO}_{2}$ methanation over supported Ni catalysts. Catal. Today 2017, 293-294, 89-96.

(40) Inui, T.; Funabiki, M.; Suehiro, M.; Sezume, T. Methanation of $\mathrm{CO}_{2}$ and $\mathrm{CO}$ on supported nickel-based composite catalysts. J. Chem. Soc., Faraday Trans. 1 1979, 75, 787-802.

(41) Fan, Z.; Sun, K.; Rui, N.; Zhao, B.; Liu, C.-j. Improved activity of $\mathrm{Ni} / \mathrm{MgAl}_{2} \mathrm{O}_{4}$ for $\mathrm{CO}_{2}$ methanation by the plasma decomposition. J. Energy Chem. 2015, 24, 655-659.

(42) Kokka, A.; Ramantani, T.; Petala, A.; Panagiotopoulou, P. Effect of the nature of the support, operating and pretreatment conditions on the catalytic performance of supported Ni catalysts for the selective methanation of CO. Catal. Today 2020, 355, 832-843.

(43) Zhao, K.; Li, Z.; Bian, L. CO2 methanation and co-methanation of $\mathrm{CO}$ and $\mathrm{CO}_{2}$ over $\mathrm{Mn}$-promoted $\mathrm{Ni} / \mathrm{Al}_{2} \mathrm{O}_{3}$ catalysts. Front. Chem. Sci. Eng. 2016, 10, 273-280.

(44) Inul, T.; Funabiki, M.; Takegami, Y. Simultaneous Methanation of $\mathrm{CO}$ and $\mathrm{CO}_{2}$ on Supported Ni-Based Composite Catalysts. Ind. Eng. Chem. Prod. Res. Dev. 1980, 19, 385-388.

(45) Deutschmann, O.; Tischer, S.; Correa, C.; Chatterjee, D.; Kleditzsch, S.; Janardhanan, V. M.; Mladenov, N.; Minh, H. D.; Karadeniz, H.; Hettel, M.; Gossler, H. DETCHEM Software Package $v 2.7,2018$. www.detchem.com.

(46) Giehr, A. Dry Reforming of $\mathrm{CH}_{4}$ : Experimental Investigations and Microkinetic Modeling Studies on a Co-based catalyst. Doctoral Dissertation, Karlsruher Institut für Technologie: Karlsruhe, 2019.

(47) Pushnov, A. S. Calculation of average bed porosity. Chem. Pet. Eng. 2006, 42, 14-17.

(48) Deutschmann, O. Modeling of the Interactions Between Catalytic Surfaces and Gas-Phase. Catal. Lett. 2015, 145, 272-289.

(49) Rostrup-Nielsen, J. R. Catalytic Steam Reforming. In Catalysis: Science and Technology; Anderson, J. R.; Boudart, M., Eds.; Springer: New York, 1984.

(50) Campbell, C. T. The Degree of Rate Control: A Powerful Tool for Catalysis Research. ACS Catal. 2017, 7, 2770-2779.

(51) Gossler, H.; Maier, L.; Angeli, S.; Tischer, S.; Deutschmann, O. $\mathrm{CaRMeN}$ : An Improved Computer-Aided Method for Developing Catalytic Reaction Mechanisms. Catalysts 2019, 9, No. 227.

(52) Stotz, H.; Maier, L.; Boubnov, A.; Gremminger, A. T.; Grunwaldt, J. D.; Deutschmann, O. Surface reaction kinetics of methane oxidation over PdO. J. Catal. 2019, 370, 152-175.

(53) Maier, L.; Schädel, B.; Herrera Delgado, K.; Tischer, S.; Deutschmann, O. Steam Reforming of Methane Over Nickel: Development of a Multi-Step Surface Reaction Mechanism. Top. Catal. 2011, 54, No. 845. 
(54) Delgado, K. H.; Maier, L.; Tischer, S.; Zellner, A.; Stotz, H.; Deutschmann, O. Surface Reaction Kinetics of Steam- and CO2Reforming as Well as Oxidation of Methane over Nickel-Based Catalysts. Catalysts 2015, 5, 871-904.

(55) Fujita, S.; Terunuma, H.; Nakamura, M.; Takezawa, N. Mechanisms of methanation of carbon monoxide and carbon dioxide over nickel. Ind. Eng. Chem. Res. 1991, 30, 1146-1151.

(56) Martin, G. A.; Primet, M.; Dalmon, J. A. Reactions of CO and $\mathrm{CO}_{2}$ on $\mathrm{NiSiO}_{\text {as }}$ above $373 \mathrm{~K}$ as studied by infrared spectroscopic and magnetic methods. J. Catal. 1978, 53, 321-330.

(57) Falconer, J. L.; Zağli, A. E. Adsorption and methanation of carbon dioxide on a nickel/silica catalyst. J. Catal. 1980, 62, 280-285.

(58) Kee, R. J.; Rupley, F. M.; Miller, J. A. Chemkin-II: A Fortran Chemical Kinetics Package for the Analysis of Gas-Phase Chemical Kinetics, No. SAND-89-8009; Sandia National Lab. (SNL-CA): Livermore, CA, 1989.

(59) CHEMKIN 10112; Reaction Design: San Diego, 2011.

(60) Goodwin, D. G.; Speth, R. L.; Moffat, H. K.; Weber, B. W. Cantera: An Object-Oriented Software Toolkit for Chemical Kinetics, Thermodynamics, and Transport Processes, 2018. https://www.cantera. org.

(61) Kechagiopoulos, P. N.; Angeli, S. D.; Lemonidou, A. A. Low temperature steam reforming of methane: A combined isotopic and microkinetic study. Appl. Catal., B 2017, 205, 238-253. 